January 2002

\title{
Taxes and Nonrenewable Resources: The Impact on Exploration and Development
}

Jeff Strnad

\section{Recommended Citation}

Jeff Strnad, Taxes and Nonrenewable Resources: The Impact on Exploration and Development, 55 SMU L. REV. 1683 (2002)

https://scholar.smu.edu/smulr/vol55/iss4/12

This Article is brought to you for free and open access by the Law Journals at SMU Scholar. It has been accepted for inclusion in SMU Law Review by an authorized administrator of SMU Scholar. For more information, please visit http://digitalrepository.smu.edu. 


\title{
TAXes AND NonRenewable \\ RESOURCES: THE IMPACT ON \\ EXPLORATION AND DEVElOPMENT
}

\author{
Jeff Strnad*
}

I. NEUTRALITY, EXPLORATION AND

DEVELOPMENT ............................ 1686

A. Nonneutrality of the Conventionally Correct

idC Treatment ............................. 1686

B. An Option Perspective ....................... 1688

II. A STYLIZED MODEL .......................... 1692

A. The Tax Treatment of Mineral Exploration,

Development, and Production .................. 1692

1. Exploration and Development Deductions ......... 1692

2. Production Stage Deductions .................... 1694

B. A Three-Phase Model........................... 1695

1. The Three Phases-Computing Threshold Prices... 1696

2. Simulated Exploration and Development.......... 1701

C. Model Limitations and Technical

Considerations............................. 1702

1. The Production Phase ....................... 1702

2. Adjusting Return Parameters for Taxes........... 1705

3. The Development Phase ....................... 1707

4. The Exploration Phase ...................... 1708

D. Tax Alternatives for Study ................ 1708

III. TAXES AND THE DEVELOPMENT OPTION ......... 1709

A. The Investment Threshold Price Formula ....... 1709

B. Probability Effects ....................... 1712

C. Percentage Depletion Effects ................... 1719

D. Well Life Effects ............................ 1719

E. Development Cost Effects...................... 1725

IV. TAXES AND THE EXPLORATION OPTION ........ 1727

A. Investment Threshold Prices.................. 1729

B. Opportunity Set Effects .................... 1732

V. SUMMARY AND CONCLUSIONS ............... 1737

* Professor of Law and Helen L. Crocker Faculty Scholar, Stanford University. I am grateful for comments from participants at the Harvard Law School Seminar on Current Research in Taxation, from workshop participants at Stanford Law School and the University of Southern California Law School, and from Joe Bankman, Dick Craswell, Barbara Fried, Tom Griffith, Mark Kelman, Ed McCaffery, David Mills, Reed Shuldiner, Eric Talley, Mark Weinstein, and Eric Zolt. The article benefited from excellent research assistance by Bill Vochoska. All errors are my own responsibility. 
VI. APPENDIX: DERIVATIONS .................... 1738

A. Deriving Net Present Value and Option Value. 1738

B. Deriving Threshold Prices for the

Development and Exploration Options ......... 1741

C. Deriving Tax Adjustments for Return

Parameters................................ 1746

D. The Value of Tax Losses Connected with the

Development Option .......................... 1748

$\mathrm{N}$

ONRENEWABLE resources such as oil and natural gas play an important role in the world economy. For instance, sharp increases in oil prices created an "energy crisis" in the developed countries in the 1970s. This crisis had major macroeconomic consequences and led to a series of policy initiatives in various countries. ${ }^{1}$ The desire of the developed countries to maintain secure oil supplies and to prevent control of those supplies by hostile powers has led to considerable international conflict. ${ }^{2}$ Taxation played a key role in many of the crisis initiatives and also has had a major influence on the development of oil and gas resources in the United States and other countries during noncrisis periods. ${ }^{3}$

Extraction of minerals, oil, or natural gas involves several phases. In an "exploration" phase, the emphasis is on finding areas with potential deposits. This phase often involves geological analysis. Exploration reduces, but does not eliminate, uncertainty about a prospect. After a promising area is identified, the "development" phase begins. For oil and gas, this means drilling a test well that will resolve much of the remaining uncertainty. If the test well is a success, development may continue through drilling enough other wells to remove the oil or gas in an efficient and timely manner. Finally, there is the "production" phase. Over a period of years, the owners operate the wells, perhaps suspending opera-

1. See, e.g., Gerard M. Brannon, Energy Taxes and Subsidies: A Report to the Energy Policy Project of The Ford Foundation 1-2 (1974); Daniel Yergin, The Prize: The EPIC Quest for Oil, Money And Power 651-698 (1991).

2. The first "oil shock" took place in 1973 and necessitated U.S. aid to Israel during the Yom Kippur War. The second oil shock began in December of 1978 and was later fueled by the Iran Hostage Crisis in November of 1979 and the Russian invasion of Afghanistan in December of 1979. These events prompted President Carter to take a hard line with the Soviet Union: "Let our position be absolutely clear. An attempt by any outside force to gain control of the Persian Gulf region will be regarded as an assault on the vital interests of the United States of America, and such an assault will be repelled by any means necessary, including military force." Yergin, supra note 1, at 702. Saddam Hussein's invasion of Kuwait in August of 1990 precipitated another oil shock and the Gulf War. See Yergin, supra note 1, at 603-06, 684-702, 769-79. The September 11, 2001 attacks on the World Trade Center initiated another round of concern about the impact of oil supply issues on U.S. foreign policy. See, e.g., Amity Shlaes, No Need to be Deterred by the Oil Weapon: U.S. Policy toward Iraq is Being Shaped by Mistaken Fears that Extending the War on Terror Would Bring a 1970s Price Shock, Fin. Times, Dec. 4, 2001, at 21.

3. See, e.g., Present Law and Proposals Relating to Increasing Domestic Energy Pro. duction and Reserves: Hearing Before the Subcomm. on Energy \& Agric. JCS-23-90 (1990); Carlo A. Favero, Taxation and the Optimization of Oil Exploration and Production: The UK Continental Shelf, 44 OXFord ECON. PAPERS 187, 188-91 (1992). 
tions when prices are low and resuming later. This article studies the impact of taxes on the development and exploration phases. ${ }^{4}$ The discussion is largely in terms of oil and gas, but many of the points apply to other extractive industries as well.

The potential impact of tax rules on exploration and development raises two concerns. First, it is desirable to exploit nonrenewable resources in an economically efficient manner. Tax incentives may cause producers to develop resources more quickly or more slowly than is economically desirable. Tax rules also may have "neutrality" consequences in that they cause producers to make the wrong choice about which projects to develop. Second, since tax rules affect the pattern of exploration and development, the rules may affect the security of supplies. For example, a policy that encourages exploration activities but that discourages immediate development of these supplies creates an inventory of known reserves that the nation may call upon in an emergency. These "national security" concerns have played a major role in public discussion of government policy with respect to oil and gas and certain "strategic" minerals. ${ }^{5}$

Part I shows that the practical (as opposed to ideal) income tax treatments that are considered "correct" may lead to serious deviations from neutrality between mineral projects with different characteristics. This is a particularly acute problem for taxation of mineral enterprises, because these enterprises consist largely of deciding when to exercise options to engage in projects with diverse traits. Part II discusses some of the main alternatives for taxing mineral enterprises and presents a stylized model that is capable of comparing these alternatives. Parts III and IV use option valuation methods to study the impact of the various tax approaches on exploration and development incentives for oil and gas. Part V presents some conclusions.

Many of the formulas in the article require stochastic calculus to derive. In addition, some of the computations require elaborate algorithms. The body of the article states results without derivation. The Appendix includes most of the key derivations and discusses the computational strategy that underlies the simulations reported in the article.

4. There are several good treatments of the production phase. See, e.g., Terry Heaps \& John Helliwell, The Taxation of Natural Resources, in 1 THE HandbooK OF Public ECONOMics 449-67 (Alan J. Auerbach \& Martin Feldstein eds., 1985); Jeffrey K. MacKieMason, Some Nonlinear Tax Effects on Asset Values and Investment Decisions Under Uncertainty, 42 J. Pub. ECON. 301 (1990) (discussing percentage depletion).

5. See, e.g., remarks of Rep. Wright, at the Nat'l Press Club on Apr. 8, 1986, quoted in 132 Cong. Rec. H1706 (daily ed. Apr. 9, 1986) (statement of Rep. Alexander); Press Release, United States Congress, Murkowski Questions Enforcement of Iraqi Oil Deal (May 20, 1996), available in LEXIS, News Group file. 


\section{NEUTRALITY, EXPLORATION AND DEVELOPMENT}

\section{A. Nonneutrality of the Conventionally Correct IDC TREATMENT}

In mineral taxation, the conventional wisdom is that provisions like the election to expense intangible drilling costs under $\S 263(\mathrm{c})$ or the availability of percentage depletion under $\S 613$ for various minerals do not have an income tax theory rationale and so must stand or fall based on incentive arguments. Consider the election to expense intangible drilling costs. Some of the cost of drilling an oil or gas well will be entirely lost if the well is a "dry hole," a well that does not have commercial quantities of oil or gas. This cost category includes the labor cost of drilling the well and certain equipment (such as drilling pipe) that cannot be removed from the well and salvaged in the event of a dry hole and corresponds approximately to the "intangible drilling costs" ("IDCs") that the taxpayer may expense. A separate cost category includes expenditures for items that the driller may salvage if the well fails. Generally, the taxpayer may recover the cost of these items only on a delayed basis through the depreciation or other cost recovery rules that apply.

Allowing the taxpayer to expense IDCs if a well fails is consistent with an ideal accretion tax. ${ }^{6}$ The value of these items is zero, and the taxpayer should be able to recognize a loss. However, in the case of a successful well, one worth more than its cost, expensing is not theoretically appropriate under accretion principles unless the tax rules simultaneously recognize "income" in the amount of the value of the well. ${ }^{7}$ Current law does not take the value of a well into income immediately after drilling. Instead it taxes receipts net of operating costs as the well produces. Combining this treatment with expensing means that the taxpayer will realize a higher rate of return than under an ideal accretion tax. ${ }^{8}$ The conventional view is that an appropriate response is to force the taxpayer to capitalize the drilling costs and recover them over time along with the operating costs. One such recovery rule is "cost depletion," where the taxpayer deducts each year the same proportion of the remaining basis as the proportion of total recoverable reserves removed from the well or mine during the year. ${ }^{9}$

6. An ideal accretion tax adds the actual receipts from an investment to the change in value of the investment during each instant and then immediately collects a tax that is a specified percentage of that sum.

7. Under accretion tax principles, the taxpayer has experienced an increase in value and should face a tax on this value at the time the well is completed even though no production has taken place. Thus, if drilling costs $\$ 500,000$ and the well is worth $\$ 700,000$ immediately after completion, then the taxpayer should recognize $\$ 200,000$ in income at that time. Effectively, the taxpayer is immediately deducting the $\$ 500,000$ but only in conjunction with recognition of the $\$ 700,000$ increase in value.

8. See infra notes 45 and 46 and accompanying text.

9. If cost depletion applies during the entire life of the well or mine and if all the depletable expenses occur up front, then each annual deduction is the proportion of initial depletable basis equal to the proportion of total initial reserves removed during that year. For many minerals, however, the taxpayer must calculate the depletion deduction for any 
There is a serious problem with this conventional approach that does not exist under the ideal accretion tax. The ideal accretion tax is "neutral" between projects: If this tax is applied to all projects, it will not change the value of any project. ${ }^{10}$ Thus, if project $\mathrm{A}$ and project $\mathrm{B}$ require the same start-up cost, but project $\mathrm{A}$ is more valuable than project $\mathrm{B}$ without considering taxes, then the same will be true after application of an accretion tax. The tax system will not distort choices among projects.

The conventional approach is nonneutral in ways that are potentially significant for extractive industries. Consider an oil and gas firm choosing between drilling two types of wells, type A and type B. Type A wells are certain to be successful in the sense that each well will produce commercial quantities of oil. Type B wells have only a ten percent chance of success, but, if successful, will produce ten times as much revenue as the type A wells. Suppose that the time pattern of production and revenue for one successful type B well will be the same as the time pattern of the revenue for ten type A wells, that the cost of drilling type A and type B wells is the same, and that the cost of operating the wells is zero. Finally, assume that the success of any given type $B$ well is independent of the success or failure of any other such well and that the firm can drill a large number of type $B$ wells.

Drilling a large number of type B wells or the same number of type A wells will tend to result in identical economic outcomes. Only about onetenth of the type B wells will succeed, but a successful type B well will produce revenue identical in magnitude and timing to the revenue from ten type A wells. Now suppose that the tax law requires that taxpayers capitalize intangible drilling costs. Since type A wells are always successful, the taxpayer will capitalize the entire amount of IDC expended on these wells. In contrast, nine-tenths of the type B wells are failures, and the taxpayer will expense the IDCs invested in these wells. The effective rule for a project that involves large numbers of type $B$ wells will be that ninety percent of IDCs are deductible and only ten percent must be capitalized. This set of "conventional" rules will favor the type B wells.

particular year using percentage depletion if that yields a larger deduction. See I.R.C. $\$ 613$ (a) (2002). As a result, in some years, the taxpayer may deduct a proportion of initial cost that exceeds the proportion of reserves removed during that year. This deduction will reduce depletable basis and lower the amount of cost depletion available in later years as a function of reserves removed. For a more extended discussion, see infra text accompanying note 28.

10. See Paul A. Samuelson, Tax Deductibility of Economic Depreciation to Insure Invariant Valuations, 72 J. PoL. ECON. 604 (1964). Professor Samuelson showed that economic depreciation, that is, deducting the decline in value of an asset during each $\operatorname{tax}$ period, results in each taxpayer valuing the asset exactly the same, regardless of the tax rate that applies to the taxpayer. Taxpayers in higher brackets receive lower net amounts because they pay higher taxes on revenues net of depreciation. However, they also have lower after-tax discount rates that make future cash flows more valuable. The two effects exactly cancel out. The same result is true for assets that appreciate or fluctuate in value. The mathematics in Professor Samuelson's proof does not depend on the sign of the value changes in the asset. 


\section{B. An Option Perspective}

The example in the previous Section illustrates an important point about mineral exploration and development projects. When a taxpayer controls the mineral rights or the development rights for a given property, the taxpayer has the right to proceed with exploration, development, or mineral production but is not obligated to do so. In short, the right to explore, the right to develop, and the right to produce mineral properties are options, and valuing any of these rights is an exercise in option valuation. At any given time a taxpayer will hold or may acquire options with respect to properties that have different characteristics. In the example, the properties differed in the probability of success and in potential reserves. Properties may also differ across other parameters, like the cost of developing the property or the time that it takes to remove the mineral deposits. Particular tax rules may favor properties with particular characteristics over properties that are economically equivalent. Part III studies the neutrality problems that arise from a variety of rules, including a rule that is equivalent to capitalizing IDCs.

Before proceeding further, it is important to illustrate the option features of mineral investments. Suppose that a particular well will cost $\$ 500,000$ to drill and complete, is certain to be successful if drilled, and will have the following production characteristics:

35,000 barrels of recoverable reserves

7 year recovery period

a constant recovery rate: 5000 barrels per year

Thus, for $\$ 500,000$, the investor will get seven years of oil production at the rate of 5000 barrels per year. Prices may change during the project, and we assume that the oil price process is driven by geometric Brownian motion:

$$
d P=\alpha P d t+\sigma P d z
$$

This equation means that prices tend to increase at the rate $\alpha$, but the rate is subject to a normally distributed perturbation with mean zero and variance $\sigma^{2} d t .^{11}$ If the required expected return on oil projects is $\mu$, then

11. Scholars studying investment in mineral industries often assume that mineral prices follow geometric Brownian motion. This assumption may be motivated more by tractability than by the desire to model the price process accurately. One leading scholar, for example, published a paper on oil exploration and development one year that relied on a geometric Brownian motion price process and published a paper the succeeding year questioning whether geometric Brownian motion is an appropriate assumption for oil prices. See Diderik Lund, Petroleum Taxation under Uncertainty: Contingent Claims Analysis with an Application to Norway, 14 EnERGy ECONOMıCs 23 (1992); Diderik Lund, The Lognormal Diffusion Is Hardly an Equilibrium Price Process for Exhaustible Resources, 25 J. EnvT'L Econ. \& MGMT. 235 (1993).

Although Professor Lund's precise arguments against the accuracy of geometric Brownian motion in representing oil prices do not apply here, there is an argument for using a mean-reverting process instead of geometric Brownian motion. There is some evidence of mean reversion in oil prices, at least if one considers the price series extending back into the last century rather than restricting tests to more recent data. Furthermore, valuations will differ significantly if one uses a mean-reverting process instead of geometric Brownian 
define $\delta$ as the difference $\mu-\alpha$. This quantity $\delta$ is the "convenience yield" for oil and can be thought of as the dividend rate for the oil project.12 Given these definitions, the net present value of investing the $\$ 500,000$ in order to do the project immediately is:

$$
N P V(P)=\frac{R P\left(1-e^{-\delta T}\right)}{\delta T}-I_{d}
$$

where $P$ is the current oil price, $R$ is recoverable reserves, $T$ is the recovery period in years, and $I_{d}$ is the $\$ 500,000$ development cost. ${ }^{13}$

The classical investment decision rule is that the investor should proceed if the project has a net present value greater than zero. This rule would be correct if the investor's alternatives were doing the project now or losing the opportunity. This feature does not characterize mineral investment opportunities. ${ }^{14}$ The individual or entity that controls the mineral or development rights may choose to delay development into the future. Sometimes such a delay is an obvious choice. Suppose, for example, that the net present value is only slightly above zero. An increase in price will drive this value up, and then net present value may be substantial. If prices are volatile, the odds of seeing a significantly higher price in the not-too-distant future are quite high (even if the expected increase, $\alpha$, is zero). As a result, the investor is clearly better off waiting.

It is worth noting that the right to do the project is valuable even if the net present value of currently engaging in the project is negative. There is a chance that prices will increase enough in the future to make the

motion. See Lead Wey, Effects of Mean-reversion on the Valuation of Undeveloped Oil Reserves and the Results of the Optimal Investment Rules (1993) (unpublished B.S. thesis, Massachusetts Institute of Technology) (on file with author).

This version does not include price computations using mean-reverting processes. Such computations are sufficiently difficult that using these processes would make it very hard, if not impossible, to derive the desired prices in a reasonable amount of time. Computing some of the numbers in this version (e.g., the ones in Tables XIX and XX infra) by making the "easy" assumption of geometric Brownian motion for the oil price process still required several days of computer time.

12. Total expected return is $\mu$, and oil prices increase at the expected rate $\alpha$. To reach the expected gain, there must be some kind of payout or return in an amount $\delta=\mu-\alpha$. Thus, one may think of $\delta$ as a dividend rate.

13. The first term on the right hand side is the present value of production. Using $R / T$ as the annual recovery rate, this term is exactly what one would get by using a conventional present value computation with a discount rate of $\delta$. Normally, the stochastic nature of $P$ means that formulas for present value will differ from conventional ones, usually including additional terms. However, the linearity of the solution here means that there will be no additional terms.

The expression in the text assumes operating costs are zero and that operation will continue until the well is depleted. Adding operating costs requires a more complex treatment because one must deal with the situation where prices fall so that the value of production is less than the operating cost to produce it. This introduces other options-the ability to abandon the project and the ability to temporarily suspend production-into the valuation.

14. Scholars have been aware of the need to analyze mineral exploration and development investments as options for at least a decade and a half. One important early paper analyzes offshore petroleum leases as options. See James L. Paddock et al., Option Valuation of Claims on Real Assets: The Case of Offshore Petroleum Leases, 103 Q. J. Econ. 479 (1988). 
project worthwhile. ${ }^{15}$

Since the investor owns an option (with no obligation) to do the project, the key task is to value that option, rather than to compute the net present value that would accrue due to immediate execution of the project. Some of the features of the option value already are evident. So long as there is some hope of future price increases, the option value is positive, even if prices are currently low and the value of immediate execution is negative. As prices increase from a low level, the value of the option will increase. A higher current price makes it more likely that the price level will reach a point in the near future where it is worth doing the project.

It turns out as a mathematical matter that there is a certain "investment threshold price," $P^{*}$, such that the investor should do the project when the actual mineral price equals or exceeds $P^{*}$. It is easy to provide some intuition for the existence of such a threshold price. When the actual price is such that the net present value of the project is zero, the investor faces no risk from waiting. Since current execution of the project would provide no surplus (in the form of positive net present value), the investor will not lose anything if prices decline. However, suppose that prices are "high" so that the project has substantial net present value if executed. In this case, a price decline will be harmful, delaying or destroying surplus that the investor could have captured immediately. At some point, the potential losses from future price declines will offset the potential gains from price increases, and the investor will opt for doing the project.

For the oil project above, the investment threshold price is $\$ 35.631$ per barrel. The price at which net present value is zero is $\$ 16.379$ per barrel. At an oil price of around $\$ 20$ per barrel, typical during the 1990 s, the project would have a net present value of about $\$ 110,000$. Nonetheless, it is optimal to wait for the price to increase to $\$ 35.631$. The following table indicates the value of the option and the net present value of immediate execution for various oil prices:

15. The only exception is where the price of the mineral declines to zero. Under geometric Brownian motion, zero is an "absorbing barrier." Once the price reaches zero, it can never be positive again. In that instance, the project never will be worthwhile. As a result, the right to do the project is worthless. 


\begin{tabular}{||c|c|c||}
\hline \multicolumn{3}{|c|}{ Table I } \\
Net Present Value and Option Value at Various Oil Prices \\
\hline oil price (\$per barrel) & net present value (in \$) & option value (in \$) \\
\hline 5 & $-347,365$ & 15,513 \\
\hline 10 & $-194,730$ & 55,956 \\
\hline 15 & $-42,095$ & 118,510 \\
\hline 16.379 & 0 & 139,458 \\
\hline 20 & 110,541 & 201,832 \\
\hline 25 & 263,176 & 305,035 \\
\hline 30 & 415,811 & 427,461 \\
\hline 35 & 568,446 & 568,591 \\
\hline 35.631 & 587,695 & 587,695 \\
\hline
\end{tabular}

Note that the option value is a substantial amount, $\$ 139,458$, when the net present value of the project is zero. Net present value may be a poor indicator of worth when ownership includes an option aspect. ${ }^{16}$

The threshold investment price is a useful instrument for studying the nonneutrality of different tax regimes. Part III considers projects with different traits that all have the same threshold price in the absence of taxes. Adding taxes produces a pattern of new threshold prices that generally differ among the various projects. The price differences indicate how the impact of the tax system varies as a function of project characteristics.

Option value analysis using threshold prices allows one to study other aspects besides neutrality. For instance, some investments are in "exploration" rather than "development." The exploration phase involves discovering whether there are any minerals in a certain area and, if so, the likelihood of recovery, the amount that is recoverable, the time required for recovery, and the cost of recovery. Choosing to explore a particular parcel amounts to purchasing a "development option" since the mineral owner has the right but not the obligation to develop the parcel after learning about the underlying minerals by spending money on exploration. Part IV analyzes exploration incentives as a function of tax treatment using the threshold price approach.

16. This point is well understood and is emphasized in elementary finance texts. See, e.g., Richard Brealey \& Stewart Myers, Principles of Corporate Finance 620-22 (6th ed. 2000) (negative NPV project may be worth doing because it gives the firm an option to do future projects that may have substantial value). 


\section{A STYLIZED MODEL}

Parts III and IV set forth the major results. This Part lays some groundwork. Section A discusses the relevant tax rules. Section B introduces the model that is the basis of the results in Parts III and IV. Section C discusses the limitations of the model, and Section D lists the major policy alternatives considered in Parts III and IV.

\section{A. The Tax Treatment of Mineral Exploration, Development, and Production}

This Section discusses the U.S. tax treatment of mineral enterprises. Although the main focus in the article is on oil and gas, some consideration is given to major rules that currently do not apply to oil and gas; these rules are examined because they may be applicable in the future.

\section{Exploration and Development Deductions}

For minerals other than oil and gas, the U.S. tax system draws a major distinction between "exploration" and "development" for purposes of specifying a tax treatment for expenditures. Section 617, which applies to most minerals other than oil and gas, ${ }^{17}$ defines mining exploration expenses as "expenditures ... for the purpose of ascertaining the existence, location, extent, or quality of any deposit or ore."18 In contrast, $\S 616$, which applies to the same class of minerals, defines development expenses as "expenditures ... for the development of a mine or other natural deposit . . . after the existence of ores or minerals in commercially marketable quantities has been disclosed."19

Section 616 allows the taxpayer to elect expensing of development costs. Section 617 allows a similar election with respect to exploration costs but provides for "recapture" when the projects reach the production stage. The recapture consists of denying depletion deductions until the total amount of the depletion that would be allowable exceeds the exploration costs that were expensed. ${ }^{20}$ However, the taxpayer may elect to take the amount expensed back into income at the time production begins and then capitalize that amount so that it is deducted over the life of the project. ${ }^{21}$ Expensing under $\S 616$ and $\S 617$ is not available for tangible property that is depreciable under $\S 167$.

The law treats oil and gas exploration and development expenses quite differently. Exploration costs must be capitalized. These costs include the cost of geological analysis of prospects, expenses of leasing a potential

17. The section applies to all minerals eligible for percentage depletion, except for oil and gas. I.R.C. $\$ 617(\mathrm{a})(1)$ (2002). Most minerals are eligible for percentage depletion, the exceptions being items like dirt and gravel.

18. $\$ 617(a)(1)$. Section 617 provides for a deduction of certain exploration expenses. Normally, the taxpayer must capitalize these expenses and recover them during the production phase of the mines or wells.

19. I.R.C. $\S 616$ (a) (2002).

20. $\$ 617(\mathrm{~b})(1)(\mathrm{B})$.

21. $\S 617(\mathrm{~b})(1)(\mathrm{A})$ 
development property, the cost of core-hole wells drilled to obtain geological data, the cost of seismic work, and other similar costs. ${ }^{22}$ Seismic work is a key component of modern exploration efforts. Seismic analysis involves sending shock waves from multiple sources into the ground. These waves travel at different speeds through formations that contain oil or natural gas, and one obtains a two-dimensional or three-dimensional diagram with "bright spots" indicating potential hydrocarbon deposits. Not all the bright spots contain deposits and some of the deposits may not be recoverable due to low porosity or other causes. A petroleum geologist can correlate the location of the bright spots with information about underground formations to sharpen the knowledge that emerges from the seismic information. At the end of this process, one has an estimate of the probability of success for drilling, as well as information about the extent of reserves, the number of wells that will be required, and the depletion rate. An actual determination of success requires drilling one or more test wells.

It is at this point that intangible drilling costs enter the picture. There are two phases to a successful oil well: drilling and completion. Drilling involves producing the bore. After the bore is finished, various tests are run that indicate (with very high probability) whether or not production is feasible. If production is not feasible, the bore is plugged and abandoned. If production is feasible, then the "completion" process begins. The well is fitted with production tubing and any equipment that may be necessary to remove the hydrocarbons. Completion costs are substantial, although usually only about a quarter to a half as large as drilling costs. An important financial point is that the investor does not pay any completion costs if it is clear from the tests that the well is not viable. A large portion of the drilling cost (including expenditures on testing) falls in the intangible drilling cost category. The investor will not recover this portion in the event of a dry hole.

It is worth noting that drilling some wells may not involve very much uncertainty. An important example is so-called "offset" wells. Suppose that a firm observes a bright spot with very large horizontal extent. It drills an initial well right into the center of the spot. This well is successful. To drain all the reserves (or to drain them more quickly), it may be best to drill several other "offset" wells into other parts of the bright spot. ${ }^{23}$ For example, the formation may not be very porous so that the first well can only remove the oil in the portion of the bright spot nearest the well bore. In this situation, the offset wells will succeed with very high probability.

The Code allows the investor to elect expensing of IDCs and draws no distinction based on the probability of drilling success or whether the well is an offset well. This treatment is very different from how IDCs would

22. See Internal Revenue Manual 4232.8-12, Exhibit 200-4.

23. "Offset" describes the fact that the well is being drilled immediately adjacent to another well that is successful and has known production characteristics. 
be treated if $\S 616$ and $\S 617$ applied. In the case of offset wells, there is a strong argument that "the existence of ores or minerals in commercially marketable quantities has been disclosed" prior to the drilling. ${ }^{24}$ The original test well already indicates the existence of hydrocarbons in the bright spot. As a result, it would be reasonable to classify IDCs as development costs under $\S 616$ in the case of offset wells. For the original test well, however, IDCs would fail the $\S 616$ requirements (to be classified as development expenses) since the existence of commercially recoverable hydrocarbons is not clear prior to drilling. The test well drilling expenses naturally fall under the definition of exploration expenses in $\S 617$ since they are spent "for the purpose of ascertaining the existence, location, extent, or quality of any deposit." 25

This discussion makes clear that the law's treatment of oil and gas differs substantially from its treatment of other minerals, primarily because $\S 616$ and $\S 617$ do not apply to oil and gas. These sections require distinguishing between drilling or digging that is exploratory and drilling or digging that is developmental, a distinction that is not employed in the oil and gas rules. ${ }^{26}$

\section{Production Stage Deductions}

Taxpayers may deduct operating expenses (such as labor) in a mining or oil and gas venture as the expenses are paid or incurred. A more complex issue is the recovery of exploration and development expenses that have been capitalized. These expenses create "depletable basis" in the property. The traditional rule is "cost depletion" which allows the taxpayer to recover each year the proportion of remaining basis equal to the proportion of remaining recoverable reserves removed during the year. ${ }^{27}$ If the only basis-reducing deductions are cost depletion deductions and if

24. The quoted language is a central part of the test in I.R.C. $\S 616(a)$ for whether expenditures are "development" expenditures.

25. $\$ 617(\mathrm{a})$.

26. The distinction is not always terribly clear in the case of minerals other than oil and gas. The difficult borderline between exploration and development expenses has resulted in a significant body of case law. 1 Boris I. BitTKER \& LawrenCe LokKen, FeDERAL TAXATION OF INCOME, EsTATES, AND GifTS $\$ 26.2 .2$, 26.2.3 (2d/3d ed., rev. vol. July 2002), available at $\mathrm{http}: / / \mathrm{www}$. riahome.com/.

Furthermore, the distinction would not necessarily be as obvious for oil and gas as the argument above seems to suggest. Not all offset wells succeed, and some may fail because the drilling takes place near the edge of the bright spot. It may not be clear that the formation characteristics will be exactly the same on the edge of the bright spot as in the middle. The porosity and the density of hydrocarbon deposit may be lower than in the center so that the reserves on the edge are not commercially recoverable. One could argue that drilling under this type of uncertainty is "for the purpose of ascertaining the existence, location, extent, or quality of any deposit or ore" rather than "for the development of a mine or other natural deposit ... after the existence of ores or minerals in commercially marketable quantities has been disclosed." I.R.C. $\$ \$ 616(a), 617(a)(1)$. That is, one could argue that the IDCs for uncertain offset wells are exploration expenses instead of development expenses.

27. Treas. Reg. $\S 1.611-2$ (a) (2002). Thus, if at the beginning of the year there were 100,000 barrels of recoverable oil left in reserves, and the taxpayer removed and sold 40,000 barrels during the year, then the taxpayer could deduct $40 \%$ of the depletable basis 
the recoverable reserves are estimated correctly in advance, then the taxpayer will deduct the basis at exactly the same rate as the reserves are removed from the well or mine.

The alternative method of basis recovery is percentage depletion. This method permits the taxpayer to deduct a percentage of the gross income from the well or mine as a depletion deduction. Percentage depletion is available for most minerals but only in special instances for oil and gas. ${ }^{28}$ In any given year the taxpayer must use whichever of percentage or cost depletion yields the largest deduction. As a result, there may be periods where basis is reduced at a more rapid rate than reserves. In that case, future cost depletion will yield a lower deduction per barrel removed than otherwise. Percentage depletion may reduce basis to zero, but not below. If the basis is zero, cost depletion will not yield any deductions. Percentage depletion is limited to $50 \%$ of the taxable income from the associated mineral property or a higher percentage $(65 \%$ or $100 \%)$ of taxable income in the case of oil and gas wells for which percentage depletion is permitted. ${ }^{29}$

\section{B. A Three-Phase Model}

The previous Section indicates that U.S. tax law draws a distinction between development and exploration. This distinction also has policy significance. In some instances, the government may want to encourage exploration as opposed to development or vice versa. For example, it may be desirable for national security purposes to have a source of domestic supply for certain minerals should foreign sources become unavailable. Pursuing such a goal may mean encouraging exploration but discouraging development and production. This scheme would encourage mineral enterprises to locate recoverable amounts of mineral but would leave the minerals in the ground for later exploitation. If foreign supplies are cut off, the government could remove the disincentives for development, and the nation would have a stream of new mineral supplies, at least for a while. ${ }^{30}$ In light of the importance of the exploration/ development distinction, a model that includes exploration, development, and production as separate phases is appropriate.

remaining as of the start of the year. This basis will have been reduced by depletion deductions from prior years.

28. I.R.C. $\$ 613 \mathrm{~A}$ details these special instances. The major special instance is that percentage depletion is permissible up to a certain amount of annual production for taxpayers who are not refiners or retailers. I.R.C. $\$ 613 \mathrm{~A}(\mathrm{c})-(\mathrm{d})(2002)$.

29. See $\$ 613 \mathrm{~A}(\mathrm{~d})(1)$ (65\% limitation for certain domestic oil and gas producers); I.R.C. $\$ 613(a)$ and $\$ 613 \mathrm{~A}(\mathrm{~b})(1)(100 \%$ limitation for certain natural gas production).

30. Section 617 would tend to bring about this result. That section allows expensing of exploration costs but penalizes development by "recapturing" the expensed costs as soon as development begins. 


\section{The Three Phases-Computing Threshold Prices}

Each of three phases-exploration, development, and production-involve an option. Exploration is an option. The mineral owner may explore a property now or may put off exploring it until later. Exploring a property reveals its development potential, but the owner does not have to develop immediately. Exercising the development option will result in wells or mines that the owner may produce, but the owner need not produce these wells or mines immediately. Part I points out that threshold investment prices are critical for gauging incentives. These prices determine when an investor will explore, develop, or produce mineral properties. So one goal is to compute threshold investment prices for each of the options.

This Section begins by describing the three phases in terms of oil exploration, development, and production. This article does not explicitly discuss exploration, development and extraction of minerals other than oil, but the article does analyze major tax policy alternatives, such as the approach implicit in $\S 616$ and $\S 617$, that do not apply to oil and gas but that do apply to other minerals. ${ }^{31}$

The first phase is exploration. To model this phase we assume that there is a large collection of unexplored properties. Each property has four key traits: oil reserves $(R)$, the number of wells required to drain the reserves $(N)$, the time required to drain the reserves $(T)$, and the probability that the property will be a successful producer $(Q)$. Prior to exploration, the $R, N$, and $T$ for any particular property are unknown, but the distribution of each trait in the set of unexplored properties is known. ${ }^{32}$

Assume that the distribution of reserves is a Weibull distribution with characteristic value 500,000 barrels and shape parameter .5. Some percentiles of this distribution are as follows:

31. Extending the model to other minerals would require only minor changes in the model structure. However, the relevant exploration, development and production parameters (such as the relative size of exploration and development costs or the time required for extraction after successful development) would be quite different for the other minerals. These differences would affect the choice of policy in ways that Parts III and IV clarify by indicating the bearing of various parameters on that choice.

32. One can think of these distributions as representing outcomes for a wide variety of U.S. onshore and offshore properties. This article aims at developing an appropriate analytic framework. I do not attempt to justify each distributional assumption via empirical evidence or otherwise. 


\begin{tabular}{|c|c|}
\hline \multicolumn{2}{|c|}{ The Distribution of Reserves } \\
\hline Percentile & $\begin{array}{c}\text { Recoverable Reserves } \\
\text { (barrels of oil) }\end{array}$ \\
\hline 1 & 51 \\
\hline 5 & 1316 \\
\hline 10 & 5550 \\
\hline 20 & 24,897 \\
\hline 30 & 63,609 \\
\hline 40 & 130,471 \\
\hline 50 & 240,227 \\
\hline 60 & 419,794 \\
\hline 70 & 724,775 \\
\hline 80 & $1,295,145$ \\
\hline 90 & $2,650,949$ \\
\hline 95 & $4,487,206$ \\
\hline 99 & $10,603,796$ \\
\hline
\end{tabular}

Assume that the distribution of well life is lognormal with a median of seven years and a .08 standard deviation. Some percentiles of the distribution are: 


\begin{tabular}{|c|c|}
\hline \multicolumn{2}{|c|}{ The Distribution of Well Life } \\
\hline Percentile & $\begin{array}{c}\text { Well Life } \\
\text { (years) }\end{array}$ \\
\hline 1 & 1.1 \\
\hline 5 & 1.9 \\
\hline 10 & 2.5 \\
\hline 20 & 3.6 \\
\hline 30 & 4.6 \\
\hline 40 & 5.7 \\
\hline 50 & 7 \\
\hline 60 & 8.6 \\
\hline 70 & 10.6 \\
\hline 80 & 13.7 \\
\hline 90 & 19.5 \\
\hline 95 & 26.1 \\
\hline 99 & 45.0 \\
\hline
\end{tabular}

The distribution for the number of wells should be conditional on the amount of reserves since recovering large, dispersed reserves may require a large number of wells. Assume a lognormal distribution with a median equal to the reserves divided by 100,000 and with a .08 standard deviation. Some percentiles for this distribution for the case where total reserves are 300,000 barrels of oil are as follows: 


\begin{tabular}{|c|c|}
\hline \multicolumn{2}{|c|}{$\begin{array}{l}\text { Table IV } \\
\text { The Distribution of Number of Wells } \\
\text { Conditional on Reserves of } 300,000 \text { Barrels of Oil }\end{array}$} \\
\hline Percentile & Number of Wells \\
\hline 1 & 1 \\
\hline 5 & 1 \\
\hline 10 & 2 \\
\hline 20 & 2 \\
\hline 30 & 2 \\
\hline 40 & 3 \\
\hline 50 & 3 \\
\hline 60 & 4 \\
\hline 70 & 5 \\
\hline 80 & 6 \\
\hline 90 & 9 \\
\hline 95 & 12 \\
\hline 99 & 20 \\
\hline
\end{tabular}

In order to learn $R, N$, and $T$ for an unexplored property, the investor must pay $I_{e}$ in exploration expenses. Upon making this payment, it is still unclear whether the reserves actually exist or whether they are recoverable if they do exist. The only way to find out for sure is to drill a test well. However, during exploration, the investor does learn $Q$, the probability that the property will be a successful producer (of reserves $R$ through $N$ wells over a time period of $T)$. With probability $(1-Q)$, the property will be unproductive. $Q$ is uniformly distributed between 0 and 1.

It is now possible to describe the exploration phase completely. The investor pays $I_{e}$, and then nature selects $R, T$, and $Q$ independently from the specified distributions. After the choice for $R$ is clear, nature chooses an $N$ from the specified distribution that is conditional on the value of $R$. When $R$ is higher (more reserves), the distribution tends to require a higher $N$ (more wells). An implicit assumption is that making a draw from the exploration pool by paying $I_{e}$ does not affect the distributions that apply to future draws. These distributions remain fixed. ${ }^{33}$

33. Assuming that the distribution for the next draw will not change is convenient for computational purposes but is somewhat unrealistic. There are some very large oil and gas deposits such as the East Texas oilfield in the United States. These extend over many "properties." Exploring properties randomly is likely to result in discovery of the largest reserve accumulations first. In addition, exploration of one property may yield significant 
After the exploration phase, the investor has a development project characterized by the four properties $R, N, T$, and $Q$. The investor may pay $I_{t}$ to drill a test well. This payment will resolve the uncertainty expressed by $Q$. If the test well indicates success, the investor may pay $I_{c}$ in order to complete the well and begin production. The investor also has the option to develop $N-1$ other wells each of which will yield $R / N$ in reserves over a time period of $T$ years. Exercising this option will cost $I_{d}$ $=I_{t}+I_{c}$, the total expense for drilling and completing a well.

Production consists of a constant flow of $R / N T$ barrels per year from each well until the well is depleted. The model here assumes that there are no operating costs and that once turned on, wells will operate until depletion. That is, the owner cannot shut a well off when faced with low prices and then turn it back on later. These assumptions are somewhat drastic. Well output usually declines over time. Wells can be shut-in and held for later production at some cost and at some risk that production potential will be reduced by interrupting production. Operating costs are generally positive. Nonetheless, as explained in a later Section, ${ }^{34}$ it greatly facilitates computing threshold prices and performing simulations if the production phase is particularly simple. Given that the focus will be on the impact of taxes on exploration and development activities, precise modeling of production is not the highest priority.

Since each phase represents a separate option, it is possible to compute a threshold investment price for each activity under various tax policy alternatives. For the development phase, the threshold price will depend on the nature of the development project, i.e., on the values of $R, N, T$, and $Q$ that characterize each such project. This dependence allows one to study whether particular tax policies have a disproportionate impact on particular types of projects. Finally, since the exploration phase is separate and distinct, one can test the impact of tax policies on oil and gas exploration by observing the different threshold investment prices that result.

information about adjoining properties. As a result, one would expect the distribution of reserves for unexplored properties for which there is no information (from nearby explored properties) to shift downward toward lower reserves at each percentile as mineral entrepreneurs explore more and more properties.

An additional problem is the assumption that the investor knows what the distribution of traits for unexplored properties is. Information about trait distributions would arise from exploration itself. At the point in time before any exploration, entrepreneurs only would have some prior beliefs about the distributions. They would be able to update their beliefs as actual exploration results became available.

For a good discussion of both of these points and an illustration of how one might update, see Louis Gordon, Estimation for Large Successive Samples with Unknown Inclusion Probabilities, 14 Advances in Applied Mathematics 89 (1993).

I do not attempt to incorporate either effect into the model here. Doing so would be particularly important if the goal were to simulate the entire time path of exploitation of a nonrenewable resource. Otherwise, one is implicitly assuming that a great deal of exploration has taken place and that the marginal impact on the trait distributions of exploring a few properties is not very large. This assumption is appropriate for domestic U.S. exploration at present.

34. See infra text accompanying notes 38-41. 


\section{Simulated Exploration and Development}

Threshold investment prices do not provide all the information that one might want. To see why, consider the intangible drilling cost example from Section I.A. That example indicates that a rule requiring capitalization of IDCs biases the investor toward low probability development projects. However, it is not clear that the class of low probability projects is very important. Consider a particular point in time. The oil price will be at some level, $P$. Investors will have explored a large number of properties, and development will be complete for properties with a threshold price less than $P$. There will be an inventory of development projects with threshold prices greater than $P$. If $P$ increases by $\$ 1$, investors will begin all the projects in the inventory that have development threshold prices between $\$ \mathrm{P}$ and $\$ P+\$ 1$. Low probability projects will tend to have very high threshold prices. Thus, the projects in inventory that are likely to be done next may tend to be high probability projects. In addition, the projects that were done in the past (with threshold prices less than $P$ ) are likely to have been mostly high probability projects. Thus, the distortion may not matter much because low probability projects are not a very large proportion of the set of promising development projects.

Part III provides some evidence on this point. Low probability projects have some importance, but the phenomenon just described does seem to lower the consequences of the distortion. This evidence does not take into account the possibility that prices will increase greatly in the future so that investors begin developing many of the low probability projects in inventory. The tax distortion might then become more significant.

To fully study the question of the importance of this tax distortion, one must know what the likely effects will be over time. Any such study should address the impact of a variety of outcomes, such as an era of very high prices. It may be that the tax distortion does not have very much impact for the "average" time series of oil prices, but that for ten percent of possible price paths, large efficiency losses will result.

An easy way to address these issues is by simulation..$^{35}$ One can choose a large number of price paths at random, and then examine the impact on the allocation of resources over time. Evaluative criteria might include: the discounted present value of oil produced; the discounted present value of the costs of exploration, development, and production; and the discounted present value of the development and exploration projects that remain at the end of the time period examined. ${ }^{36}$ The variation of these criteria as well as their average tendency under different tax policies would be interesting. The model here provides a basis for such simu-

35. The alternatives of proving theorems or deriving formulas may be extremely difficult. See, e.g., infra text accompanying notes 79-111 (Monte Carlo simulation used to compute exploration threshold prices).

36. The simulation would begin with a finite number of unexplored properties and would limit the number of properties that could be explored during any given time period. 
lations, but I leave actual simulations to future work. It is important to keep in mind the limitations of threshold investment price analysis and also the possibility of using a simulation approach to override those limitations.

\section{Model Limitations and Technical Considerations}

Understanding some important limitations of the model requires a discussion of some technical, but intuitive, points.

The three phases in the model create three layers of option. Exercising the exploration option by paying $I_{e}$ yields a development option. Exercising the development option by paying $I_{t}$ yields a production option. Exercising the production option requires paying $I_{c}$ to complete the test well and $I_{d}$ per well to drill and complete each other well. The result is $N$ producing wells.

Solving for the values of the various options requires "working backward." 37 For instance, to value the development option, one needs to know the value of the various production options that may ensue since exercising the development option will result in a production option. This solution process means that complexity at the "late" stages like production will make computation at the earlier stages difficult. It will be necessary to make many late stage computations to value options at the earlier stages since each earlier stage option will be a weighted average of many possible later stage options. The rest of this Section discusses this point more precisely and also details the modeling limitations for the production and development phases that are necessary to be able to compute investment threshold prices for the exploration option.

\section{The Production Phase}

Consider again the production option discussed in Part I.B above. Starting production from a well (by drilling and completing it) has a certain net present value that depends on the current oil price. The owner may choose to wait for the oil price to go higher before producing. When oil prices are low and the net present value of producing is low or negative, the option to produce is more valuable than starting production. As prices increase, however, there is a penalty to delay: If prices fall, the owner may lose an opportunity to start the project when it has a high net present value. A similar opportunity may not arise for a long time since it may take prices a while to return to their present high level. If the oil price reaches or exceeds a certain "investment threshold price", the investor should start producing. Option value will equal net present value at all prices above the investment threshold price since the investor will exercise the option and begin producing in response to any such price. In

37. For a good elementary discussion of solution methods for this type of problem, see Avinash K. Dixit \& Robert S. Pindyck, Investment under UnCertainty 319-28 (1994). 
effect, the net present value function and the option value function are "pasted" together (and become identical) at the investment threshold price.

How does one find the investment threshold price? It is possible to compute a value for the option as a function of the oil price up to an unknown constant and also to compute net present value as a function of the oil price. One then solves for the unknown constant and the investment threshold price using two equations: a value equation, and a smooth pasting equation. The value equation sets the value of the option equal to the expression for net present value. This equation would immediately yield the investment threshold price if we knew the unknown constant in the option value. The smooth pasting equation requires that the option value and net present value functions meet smoothly at the investment threshold value point where the functions are "pasted" together. ${ }^{38}$ Using this equation along with the value equation yields the unknown constant and the investment threshold price.

The significance of this solution method is that the ability to solve each stage easily depends on having convenient expressions for the values of the later stage. Suppose, for example, that we did not have a formula for net present value as a function of oil price but had to make a numerical estimate each time we wanted to know net present value for a particular price. Then, even if we knew the unknown constant in the option value expression, we could not solve the value equation explicitly. Instead we would try various prices using a system that promises to bring us closer to the actual investment threshold price after each step. If we try a price that results in option value in excess of net present value, we know that the trial price is too low. On the other hand, a price that has the opposite consequence is too high. We would then try a price in between and continue the process until we are within some tolerable interval of the correct result.

Using this approach to find the investment threshold price for a few production projects would not be difficult. The problem arises in solving for the investment threshold price for the other phases, especially the exploration phase. Approximating the exploration threshold price requires computing the value of the production project (as a function of price and other parameters) millions of times. If each of these millions of calculations involved a numerical approximation algorithm, it probably would be impossible to estimate the exploration threshold price in a reasonable amount of time.

Unfortunately, some of the production features that one might wish to include lead to exactly this type of problem. For example, including operating costs in the production model makes it necessary to specify what

38. The derivatives of the functions must be equal at the investment threshold price. This condition is necessary for optimality. Otherwise, it would be better for the investor to start producing at a higher or lower price. For an elementary explanation, see Dixit \& Pindyck, supra note 37 , at 130-32. 
happens if prices fall, production declines, or costs increase to the point where the well is operating in the red. In the real world, operators will either "shut-in" the well, hoping to resume operations later, or will abandon and plug the well. Adding an option to suspend operations or an option to terminate them (prior to draining all the reserves) means that one must solve for additional threshold prices (for abandonment, suspension, and start up after suspension) simultaneously with solving for the investment threshold price (for initial start-up of production). The resulting equations are typically nonlinear in a way that precludes writing down a formula for the investment threshold price. ${ }^{39}$ Furthermore, solving such nonlinear equations by approximation relies heavily on starting with "good guesses." 40 If an algorithm has only a small chance of failing, it will be inadequate when the threshold price for the production option needs to be computed millions of times in order to compute a threshold price for exploration.

These considerations lead to use of the simple model described above with no operating costs and no option to suspend operations in hope of higher future prices. Using a simple model of this sort means that only very rough modeling of the tax features for the production phase is possible. In particular, it is impossible to capture all the features of current depletion policy. This policy includes an income test and shifting back and forth between percentage depletion and cost depletion. Since there are no operating costs in our model, it is hard to include the income test in any realistic way. Furthermore, modeling the switching between percentage and cost depletion in a stochastic environment is tricky. ${ }^{41}$

As a result of these limitations, I consider only a very simplified version of percentage depletion. Instead of applying a tax rate, $s$, to the costless revenues that flow from the project, the tax rate is adjusted to allow for percentage depletion at a rate $\eta$. The adjusted tax rate is $s(1-\eta)$. Furthermore, I add percentage depletion as a bonus to cost depletion, if any. This bonus approach avoids having to model shifts between cost depletion and percentage depletion. This simple version of percentage depletion is equivalent to a negative severance tax at rate $\eta s$. Using a negative (and linear) severance tax to model percentage depletion may be a good rough approximation, ${ }^{42}$ but it clearly misses effects that arise from the fact that the actual percentage depletion allowance is nonlinear. ${ }^{43}$

39. See id. at 218, 233-34.

40. See William Press et al., Numerical Recipes: The Art of Scientific ComPUTING 241 (1987).

41. The leading study of percentage depletion assumes that capital expenditures are expensed. See MacKie-Mason, supra note 4, at 310 . As a result, there is no basis for cost depletion, and no need to consider switching back and forth. The ensuing analysis ends up being complicated enough and culminates in some numerical simulations. See id. at 322-24.

42. See Heaps \& Helliwell, supra note 4, at 456-57.

43. See MacKie-Mason, supra note 4, at 301-03, 325 (showing the importance of considering the interaction of nonlinear tax rules with uncertainty and using percentage depletion as one example). 
There is an additional simplification for the cases where the rules call for capitalizing exploration or development expenses and recovery through cost depletion. Since the level of taxable income during production does not affect percentage depletion and since production of each well will continue at a known rate until exhaustion at a known future time, it is possible to "front load" the capitalization of expenses. The exact time pattern of production is known in advance so that the time pattern of cost depletion allowances is also known. I assume that $r$, the riskless interest rate, is fixed throughout time and is the same for all maturities. As a result, if the taxpayer incurred $\$ X$ in capitalized expenditures, then at the time production starts, the taxpayer will receive a flow of depletion deductions worth

$$
\frac{1-e^{-r T}}{r T} X
$$

as of that time. Front-loading the depletion deductions rather than considering them as a flow simplifies the analysis.

Another consequence of not having a realistic model of percentage depletion is that it is difficult to model $\S 617$ precisely. That section allows the expensing of exploration costs, but then recaptures them by eliminating percentage depletion until total percentage depletion exceeds the amount expensed. The taxpayer may elect an alternative treatment where the amount expensed becomes income when production begins, is capitalized at that point, and then is recovered through depletion. Instead of modeling $\$ 617$ explicitly, Parts III and IV consider a policy where the elective treatment is mandatory. This approach is called "expensing with recapture."

The following equation expresses the present value of producing $\mathrm{R}$ barrels of reserves at a constant rate over a time period of $T$ through $N$ wells that $\operatorname{cost} I_{d}$ each to develop: ${ }^{44}$

$$
N P V(P)=\frac{R P(1-s+\eta s)\left(1-e^{-\delta T}\right)}{\delta T}-N I_{d}\left[\left(1-c_{d}\right)(1-s)+c_{d}\left(1-s \frac{1-e^{-r T}}{r T}\right)\right]
$$

where $r$ is the riskless rate, $\delta$ is the required "dividend" rate, $s$ is the tax rate, $\eta$ is the rate of percentage depletion, and $c_{d}$ is one if development costs are capitalized and zero if they are expensed.

\section{Adjusting Return Parameters for Taxes}

In the equation for $N P V(P)$ it appears that neither $\delta$ nor $r$ is adjusted for taxes. $\delta$ is the difference between the risk adjusted expected return, $\mu$, and the expected growth rate for the oil price, $\alpha . \mu$ is equal to the riskless rate, $r$, plus some risk premium, $\gamma$. The required pre-tax or no-tax values of $r$ and $\gamma$ may differ from the required after-tax values. Whether or not

44. This expression ignores exploration costs, implicitly assuming the taxpayer may expense these costs without facing any recapture when production begins. 
there is a difference depends on the relationship between the oil and gas tax rules and the "external tax environment," the rules applied to the rest of the sectors of the economy. We assume that the oil and gas sector is small enough compared to all other sectors, that required after-tax rates of return, $r$ and $\gamma$, will be set in the outside sectors.

The risky portion of the returns consist of the revenues represented by the first term on the right hand side of the $N P V(P)$ equation. This portion is being taxed on a cash flow basis at rate $(1-s+\eta s)$. If a cash flow tax applies to the outside sectors as well, then the pre-tax riskless rate from these sectors, and the risk premium (appropriate to oil and gas) that follows from these sectors will apply without modification to the oil and gas sector. ${ }^{45}$ The equation for $N P V(P)$ above will be correct under the interpretation that $r$ and $\gamma$ (and thus $\delta$ ) equal their pre-tax values.

A different situation arises if the external tax is not a global cash flow tax. Suppose, for instance, that the outside sectors are taxed using a uniform accretion tax at rate $t_{A}$. If $r_{p}$ is the pre-tax riskless rate, the after-tax riskless rate in the outside sectors will be $r_{p}\left(1-t_{A}\right)$. Since we assume that the outside sectors are very large compared to the oil and gas sector, the after-tax riskless return in the oil and gas sector also will have to be $r_{p}(1-$ $\left.t_{A}\right)$. The fact that this riskless rate differs from $r_{p}$ will have a second order impact on $\gamma_{p}$, the pre-tax risk premium. ${ }^{46}$ We will have to use the following values for $r$ and $\delta$ in the equation for $N P V(P)$ and all other equations that depend on $r$ and $\delta$ :

$$
\begin{gathered}
r=r_{p}\left(1-t_{A}\right) \\
\delta=r_{p}\left(1-t_{A}\right)+\gamma_{p}\left(1-\frac{r_{p} t_{A}}{1+r_{p}-\alpha}\right)-\alpha
\end{gathered}
$$

where $\alpha$ is the expected growth rate of the oil price.

45. Under a cash flow tax, the investor receives an immediate deduction for amounts invested. This deduction reduces the after-tax investment amount by the proportion (1$s)$, where $s$ is the tax rate. At the same time, the investor gives up the same proportion, (1 $-s)$, of all future returns. As a result, the investor effectively holds the proportion $(1-s)$ of the investment and will require the same riskless rate of return and risk premium as for the original investment. The government holds the remaining proportion, $s$.

This argument assumes away any general equilibrium effects that might impact the riskless rate of return or the risk premium. These effects could arise because the government redistributes its portion to people with different risk tolerance or time preference characteristics than the original owners. I ignore any such effects.

46. The cash flow tax still cuts investment costs and returns by the same amount. To first order, then, the risk premium should be the same. However, the change in the riskless rate has a small impact on value, and rate-of-return risk depends, roughly speaking, on the fluctuation of returns versus value. As a result, there is a small ("second order") change in the risk premium, $\gamma_{p}$. 


\section{The Development Phase}

As discussed previously, a development project is the opportunity to gain with probability $Q$ an option to produce $N$ wells that will yield reserves of $R$ over a period of $T$ years. There is some investment threshold price for exercising the development option. Call this price $P_{2}^{*}$ where the subscript "2" symbolizes that development is the second phase. If development is successful, then the investor will hold a production option with a separate investment threshold price that we will call $P_{3}{ }^{*}{ }^{47} \mathrm{I}$ assume that development takes place instantaneously. ${ }^{48}$ Under this assumption, $P_{3}{ }^{*}$ will be less than $P_{2}{ }^{*}{ }^{49}$ This inequality means that the production option collapses into the development option: Exercising the development option (because the oil price, $P$, is above $P_{2}^{*}$ ) implies that one also will exercise the production option (since the oil price also will exceed $P_{3}{ }^{*}$ ) if development is successful. ${ }^{50}$ As a result, it is only necessary to compute an investment threshold price for the development option. The investment threshold price for the production option is not meaningful since the investor always will exercise this option following successful development.

A similar collapse does not occur between the exploration option and the development option. Exploration means paying a sum, $l_{e}$, in order to draw a development project at random. These development projects will have a wide range of investment threshold prices. Some of these will be below the oil price that justifies exploration, and some will be above that price. As a result, the investor will not always immediately execute the development option that flows out of exploration. ${ }^{51}$

47. The subscript " 3 " stands for the fact that production is the third stage, following exploration (stage 1) and development (stage 2).

48. Failing to make this assumption would mean that the model would have to take into account the possibility that oil prices will change during the development period. This possibility would require modeling an option to abandon development (if prices fall enough) and would require considering changes in $P_{3}^{*}$ that may occur in the interim. The ensuing complexities would make computing the value of the exploration option very difficult.

49. It is easy to see why the inequality is true. It costs some amount of money, $I_{t}$, to exercise the development option. If one knows that prices are too low for immediate execution of the ensuing production project, it is worthwhile waiting until prices increase at least to the point where immediate execution is justified. In the meantime, one can earn interest on the amount $I_{t}$, the cost of exercising the development option. Thus, the investor will not exercise a development option unless prices increase above the threshold price, $P_{3}^{*}$, for starting production. As a consequence, the investment threshold price for development, $P_{2}^{*}$, must be greater than or equal to $P_{3}^{*}$, the investment threshold price for production.

50. If development is not successful, there will never be any production, and the production option will be worthless.

51. In fact, if the oil price is at or slightly above the level that justifies exploration, immediate development will be exception rather than the rule. See infra text accompanying notes $90-95$ (at the exploration threshold price, the probability of immediate development is in the $5 \%$ to $10 \%$ range). 


\section{The Exploration Phase}

Since exploration is a random draw from the set of possible development projects, there may be a substantial or even indefinite delay in recovering expenses that are capitalized. This delay will occur if the development project has an investment threshold price far above the current oil price. The law is fairly firm in putting off the deduction of expenses for low value projects, recognizing, in the spirit of option theory, that these projects may have value in the future. ${ }^{52}$

In some cases, however, the taxpayer has another alternative. If the development option is worth less than the total exploration cost, then the taxpayer can sell the option and take a loss. Furthermore, low value development options that are worth somewhat more than the total exploration cost may fall below that level if oil prices fall. In effect, the taxpayer has a "timing option" to realize losses for development options. 53 Including this timing option in the analysis would be complex, so I do not do so. Failure to include it means that the increases in investment threshold price for the exploration option due to forcing capitalization of exploration costs observed in Part IV are biased upwards. ${ }^{54}$ Approximating the impact of tax loss trading indicates that the prospect of such trading may reduce the impact of capitalization by as much as $80 \% .^{55}$

\section{Tax Alternatives for Study}

Parts III and IV will examine twelve tax alternatives. These twelve alternatives emerge from three alternatives for the treatment of exploration expenses, two alternatives for the treatment of development expenses, and the decision about whether or not to allow percentage depletion.

For exploration costs, the three alternatives are capitalization, expensing, or expensing with recapture. As discussed above, expensing with recapture means that the taxpayer may deduct the exploration costs when

52. There must be an "identifiable event" demonstrating that an exploration expenditure is worthless before the owner may deduct the expenditure. Such an event might be the abandonment of a lease on the explored property or "any event" that establishes that the information gained by the exploration expense is worthless. See Rev. Rul. 77-188, 1977-1 C.B. 76; Rev. Rul. 83-105, 1983-2 C.B. 51. Rev. Rul. 83-105 demonstrates, using examples, how different projects are evaluated under Rev. Rul. 77-188. Of particular interest is "Situation 6," in which no deduction is allowed for exploration expenditures related to a tract that the taxpayer claimed had "no potential mineral production," because the taxpayer retained the property. The reasoning is that by retaining the property instead of abandoning it, the taxpayer demonstrated that the exploration expenses allocated to this property were not worthless.

53. See George M. Constantinides, Capital Market Equilibrium with Personal Tax, 51. ECONOMETRICA 611 (1983) (timing option for common stock).

54. If the current oil price is just on the threshold where exploration is desirable, it appears that a large proportion of the development project "draws" will be worth less than the exploration costs expended to make the draw. For the central case considered in Part IV, the proportion is close to $60 \%$ of all development projects that are not immediately executed. See infra text accompanying note 86. Thus, it is not possible to dismiss tax-loss selling as trivial.

55. See infra note 86 and accompanying text. 
incurred, but, at the time production begins (if ever), the taxpayer must include these costs in income and then capitalize them according to the cost depletion rules.

For development costs, the two alternatives are capitalization and expensing. Because exercising a development option means that the investor will move immediately to production, a rule of expensing with recapture is equivalent to capitalization. There is no delay between the deduction of expenses and the time when the expenses come back into income and are capitalized. Thus, there is no reason to consider a separate rule of expensing with recapture in the case of development costs.

Finally, Parts III and IV consider two cases for percentage depletion: no percentage depletion and percentage depletion at a $22.5 \%$ rate. All twelve tax scenarios use a tax rate of $40 \%$. Thus, the $22.5 \%$ percentage depletion allowance reduces the tax rate on production from $40 \%$ to $31 \%$.

\section{TAXES AND THE DEVELOPMENT OPTION}

This Part studies the impact of various tax regimes on the development option by examining how each regime affects the investment threshold prices for various development projects. Section A sets forth the formula for $P_{2}^{*}$, the investment threshold price, and discusses certain aspects of the formula. Sections B, D, and E consider the impact of various tax rules on projects with different probabilities of success, on projects with different production lives, and on projects with different development costs, respectively. Section $\mathrm{C}$ considers the impact of percentage depletion on the investment threshold price.

\section{A. The Investment Threshold Price Formula}

The investment threshold price, $P_{2}^{*}$, is given by:

$$
P_{2}^{*}=\frac{\beta_{1}}{\beta_{1}-1} \frac{\delta T}{\left(1-e^{-\delta T}\right)} \frac{1}{R Q(1-s+\eta s)} \times\left[\begin{array}{c}
Q N I_{d}\left(\left(1-c_{d}\right)(1-s)+c_{d}\left(\frac{1-e^{-r T}}{r T}\right)\right) \\
-Q s I_{e}\left(c_{r}\left(\frac{1-e^{-r T}}{r T}-1\right)+c_{e}\left(\frac{1-e^{-r T}}{r T}\right)\right) \\
+(1-Q)\left(I_{t}(1-s)-c_{e} I_{e} s\right)
\end{array}\right]
$$

$Q=$ the probability development will succeed

$R=$ total reserves

$N=$ number of wells required to recover reserves

$T=$ time period required to recover reserves

$\delta=$ required after-tax "dividend" rate

$r=$ the after-tax riskless interest rate

$s=$ tax rate 
$\eta=$ percentage depletion rate

$I_{d}=$ cost to drill and complete a well

$I_{e}=$ exploration cost for the property

$I_{t}=$ cost to drill, but not complete, a well

$c_{d}=0$ if development costs are expensed, 1 if capitalized

$c_{r}=1$ if exploration costs are expensed with recapture, 0 otherwise

$c_{e}=0$ if exploration costs are expensed, 1 if capitalized ${ }^{56}$

$\beta_{1}=\mathbf{a}$ factor depending on $r, \delta$, and the volatility of oil prices ${ }^{57}$

It is easy to understand this equation by transposing some of the terms from the right hand side onto the left hand side:

$$
\frac{p_{2}^{*} R Q(1-s+\eta s)\left(1-e^{-\delta T}\right)}{\delta T}=\frac{\beta_{1}}{\beta_{1}-1} x\left[\begin{array}{c}
Q N I_{d}\left(\left(1-c_{d}\right)(1-s)+c_{d}\left(\frac{1-e^{-r T}}{r T}\right)\right) \\
-Q s I_{e}\left(c_{r}\left(\frac{1-e^{-r r}}{r T}-1\right)+c_{e}\left(\frac{1-e^{-r T}}{r T}\right)\right) \\
+(1-Q)\left(I_{t}(1-s)-c_{e} I_{e} s\right)
\end{array}\right]
$$

The left hand side is the probability-adjusted present value of after-tax revenues that will flow from development, ${ }^{58}$ and the term in square brackets on the right hand side is the probability-adjusted after-tax cost of proceeding with development. The cost factor is inflated by an "option multiple" equal to $\beta_{1} /\left(\beta_{1}-1\right)$. This option multiple is greater than one. ${ }^{59}$ As a result, the investment threshold price, $P_{2}{ }^{*}$, must be large enough so that the revenue factor exceeds the cost factor by the option multiple. ${ }^{60}$

56. Note that $c_{r}$ and $c_{e}$ cannot both be equal to 1 . One or both must equal 0 .

57. $\beta_{1}$ is somewhat less than 2 in the cases presented in this Part and Part IV. The formula for $\beta_{1}$ is:

$$
\beta_{l}=\frac{1}{{\sigma_{p}}^{2}}\left[\left(\frac{l}{2} \sigma_{p}^{2}-r+\delta\right)+\sqrt{\left(\frac{1}{2} \sigma_{p}^{2}-r+\delta\right)^{2}+2 r \sigma_{p}^{2}}\right]
$$

where $\sigma_{p}^{2} d t$ is the variance of the rate of change in oil prices over a small time interval, $d t$.

58. See supra equation accompanying note 44 .

59. $\beta_{1}$ ranges from one to infinity. As it does so, the option multiple ranges from infinity down to one. $\beta_{1} /\left(\beta_{1}-1\right)$ is one when there is no oil price risk, and it increases monotonically with the volatility of oil prices. This pattern reflects the fact that options are more valuable when there is more risk with respect to the object of the option.

This section reports investment threshold prices for both an accretion external tax and a cash flow external tax. The corresponding values of $\beta_{1}$ for the two environments are 1.68 and 1.85 , respectively, and the corresponding option multiples are 2.48 and 2.18 , respectively. When the external tax is an accretion tax, the applicable after-tax discount rate is lower, and investors will be more patient. As a result, the option will require a higher oil price in order to start production as reflected in the higher value of multiple $\beta_{1}$ when the external tax is an accretion tax.

60. If there were no price risk, that is, no possible change in oil prices, the investment criterion would be net present value. In this case, the option multiple would be one, and $P_{2}^{*}$ would be the price that makes net present value zero. 
It is worth discussing the terms in the cost factor. The cost factor includes terms in $I_{e}$, exploration cost. These terms are only relevant if exploration costs are capitalized or expensed and recaptured. ${ }^{61}$ Expensing with recapture $\left(c_{r}=1\right)$ will come into play only if development is successful. In addition to the sunk exploratory costs, the investor must spend $I_{t}$ on a test well regardless of whether development succeeds or fails. The last term in the cost factor reflects the fact that with probability $(1-Q)$ development will fail, and the investor will be able to write off $I_{t}$ and any exploratory costs that were capitalized. ${ }^{62}$

The first term in the cost factor represents the treatment of development costs for the case where the development is successful. As a result, this term is multiplied by the probability, $Q$, of success. The term is also multiplied by $N$, the number of wells required, since the taxpayer must pay $I_{d}$ per well to develop the property. When $N$ is larger, development costs will loom larger relative to exploration costs in the cost factor, and the cost factor itself will be larger. A larger cost factor means that the investment threshold price will be larger. This pattern makes sense. An investor will require a higher reward to exercise an option if the price of exercising it is higher.

The first part of the second term in the cost factor represents the penalty that occurs if expensed exploratory costs are recaptured. ${ }^{63}$ The penalty rate is equal to the present value of capitalizing a dollar of costs minus the present value of deducting that dollar. Thus, the "expensing plus recapture" approach for exploratory expenses will tend to encourage exploration but discourage development.

The following Sections contain tables with investment threshold prices computed under various assumptions. In order to compute these prices, it is necessary to use particular values for the parameters in the equation for $P_{2}{ }^{*}$ above. The rest of this Part uses the following parameter values in all the tables:
$r_{p}$ (pre-tax riskless rate $)=.05$
$\alpha$ (expected growth rate of oil prices) $=.04$
$\gamma_{p}($ pre-tax risk premium $)=.03$
$s($ tax rate $)=.4$
$\eta$ (percentage depletion rate $)=0$ or .225
$I_{d}$ (development cost per well) $=500,000$
$I_{e}$ (exploration cost per property) $=100,000$
$I_{t}$ (cost to drill test well) $=375,000$

61. The mathematics indicates this point by the fact that either $c_{r}$ or $c_{e}$ must be one for the terms to matter. If exploration cost is expensed (i.e., if $c_{r}$ and $c_{e}$ are both zero), then it has no impact on the decision to develop since it is a sunk cost that has already been fully deducted.

62. If the taxpayer expensed the exploratory costs, then there will be no further recovery if development proves that the project is a failure. $c_{e}=0$.

63. If the policy of expensing exploratory costs with recapture applies, then $c_{r}=1$, and 
The results use two alternative external taxes to derive after-tax discount rates. One external tax is a cash flow tax. This external tax implies that the after-tax riskless rate, $r$, and the after-tax required "dividend" rate, $\delta$, will be equal to their pre-tax values. In other words, $r=r_{p}=.05$, and $\delta=$ $r_{p}+\gamma_{p}-\alpha=.04$. The other external tax is an accretion tax at a twenty percent rate. This external tax will cut the after-tax riskless return required in the oil and gas sector to $r=r_{p}(1-.2)=.04$ from .05 , and the after-tax required dividend rate will be $\delta=.0297 .64$

Well parameters $Q$ (probability of successful development), $R$ (total recoverable reserves), $N$ (number of wells required), and $T$ (time period required to recover reserves) vary from case to case.

\section{B. Probability Effects}

An earlier Section argued that capitalizing intangible drilling costs might have differential effects on development projects with different probabilities of success. The following table considers a series of development projects involving ten wells with a well life of seven years each. The projects differ in the probability of successful development, but total reserves are set for each project so that in the absence of taxes, the threshold price for development would be $\$ 16$ per barrel. The table reports development threshold prices for various tax scenarios.

The first column of numbers is simply the probability of development success for each project. The second column reports the results for expensing of both exploratory and development costs. These results are identical to the no-tax results: $\$ 16$ is the threshold price for each project. This pattern occurs because we are assuming an external cash flow tax. Expensing of all costs means that cash flow taxation applies internally as well. As a result, we have a global cash flow tax, and this tax will not affect value or prices, at least in the absence of general equilibrium effects. ${ }^{65}$

The fifth column is a case that focuses on the policy of capitalizing IDCs since development costs are capitalized. ${ }^{66}$ Exploratory costs are expensed. High probability projects suffer higher threshold prices, ranging up to $\$ 17.67$ per barrel for a "sure thing" situation. When the probability of success is only .01 , the threshold price is $\$ 16.20$, very close to the $\$ 16$ no-tax price. In this case, there is a .99 probability that the taxpayer will be able to write off the cost of the test well, and only a .01 probability that the taxpayer will have to capitalize any costs. As a result, this case is

64. See supra equation accompanying note 46 (formula for $\delta$ ).

65. See supra note 45.

66. Development costs include the cost of tangible equipment that is subject to depreciation and is salvageable if a well turns out to be a dry hole. I ignore this "tangible" component throughout the article and assume that all development costs are "intangible drilling costs." This assumption would be correct if the taxpayer rented any depreciable equipment that was used in development. The rental cost then amounts to an intangible drilling cost since the taxpayer will not recover the rental cost through oil production for any well that is a dry hole. 


\begin{tabular}{|c|c|c|c|c|c|c|}
\hline \multicolumn{7}{|c|}{$\begin{array}{l}\text { Investment Threshold Price for the Development Option } \\
\text { Various Probabilities of Successful Development } \\
\text { Number of Wells }=10 \\
\text { Well Life }=7 \text { years } \\
\text { External Tax is Cash Flow or None } \\
\end{array}$} \\
\hline \multirow[b]{2}{*}{ probability } & \multicolumn{3}{|c|}{ expense development costs } & \multicolumn{3}{|c|}{ capitalize development costs } \\
\hline & $\begin{array}{l}\text { expense } \\
\text { exploration } \\
\text { costs }\end{array}$ & $\begin{array}{l}\text { capitalize } \\
\text { exploration } \\
\text { costs }\end{array}$ & $\begin{array}{l}\text { expense } \\
\text { exploration } \\
\text { costs with } \\
\text { recapture } \\
\end{array}$ & $\begin{array}{l}\text { expense } \\
\text { exploration } \\
\text { costs }\end{array}$ & $\begin{array}{l}\text { capitalize } \\
\text { exploration } \\
\text { costs }\end{array}$ & $\begin{array}{c}\text { expense } \\
\text { exploration } \\
\text { costs with } \\
\text { recapture }\end{array}$ \\
\hline .01 & 16.00 & 13.47 & 16.00 & 16.20 & 13.67 & 16.20 \\
\hline .05 & 16.00 & 14.25 & 16.01 & 16.69 & 14.94 & 16.70 \\
\hline .1 & 16.00 & 14.75 & 16.02 & 17.00 & 15.74 & 17.01 \\
\hline .2 & 16.00 & 15.21 & 16.03 & 17.28 & 16.49 & 17.31 \\
\hline .3 & 16.00 & 15.42 & 16.03 & 17.42 & 16.84 & 17.45 \\
\hline .4 & 16.00 & 15.55 & 16.03 & 17.50 & 17.05 & 17.53 \\
\hline .5 & 16.00 & 15.63 & 16.03 & 17.55 & 17.18 & 17.58 \\
\hline .6 & 16.00 & 15.69 & 16.03 & 17.59 & 17.28 & 17.62 \\
\hline .7 & 16.00 & 15.74 & 16.03 & 17.61 & 17.35 & 17.65 \\
\hline .8 & 16.00 & 15.77 & 16.03 & 17.64 & 17.41 & 17.67 \\
\hline .9 & 16.00 & 15.80 & 16.03 & 17.65 & 17.45 & 17.69 \\
\hline 1.0 & 16.00 & 15.82 & 16.03 & 17.67 & 17.49 & 17.70 \\
\hline
\end{tabular}

close to total expensing, a policy that would yield exactly the no-tax threshold price of $\$ 16$.

Returning to the third column, capitalizing exploration costs results in similar effects. For low probability projects, there is a high likelihood that the taxpayer will be able to deduct the previously capitalized exploration costs immediately. This reduces total expected costs and permits a lower threshold price. Thus, the threshold price increases with the probability of development success. Note also that all the threshold prices in the third column are less than $\$ 16$, the no-tax threshold price. Allowing the taxpayer to expense or capitalize exploration costs when and only when development begins is a "tax bonus" that encourages development, lowering the threshold price. The taxpayer has spent the exploration costs in the past, and, consequently, they do not have any non-tax impact on total expected costs or the development threshold price. Part IV will show that this policy simultaneously significantly increases the exploration threshold. Thus capitalizing exploration expenses causes less exploration 
combined with more intensive immediate development of the explored areas.

Turning to the fourth column, it appears that recapture of expensed exploration costs has little impact on the development threshold price compared to the case where exploration costs are capitalized. There are two reasons that explain the small size of the effects. First, the "recapture penalty," the tax detriment due to recapture of previously expensed exploration costs, typically is much smaller per dollar of exploration cost than the tax benefit of being able to deduct, over a period of years, previously capitalized exploration costs. To illustrate the difference in magnitude, consider the "capitalization factor," the discounted present value of the deductions that flow from capitalizing one dollar of costs. ${ }^{67}$ The factor averages about .86 .68 Thus, for every dollar of capitalized exploration costs, the decision to develop means that the taxpayer will realize a stream of deductions with present value equal to .86. The recapture penalty is one minus the capitalization rate since this penalty brings previously expensed costs into income and then allows the taxpayer to recover them over time. Given a capitalization rate of .86 , the recapture penalty is .14 per dollar of exploration costs, about a sixth as large as the capitalization rate. Second, the recapture penalty only comes into play when the development project succeeds. ${ }^{69}$ In that case, the development costs of $\$ 5,000,000$ ( $\$ 500,000$ each for ten wells) are fifty times larger than the exploration costs $(\$ 100,000)$. Since the recapture penalty applies to exploratory costs, it will create very little change as a proportion of total cost and, consequently, will have very little effect on the threshold price for development. ${ }^{70}$

One might suspect that the recapture penalty would have more impact if development were cheaper. The next table indicates that this reasoning is correct, presenting development threshold prices for the case where development costs are much lower relative to exploration costs because only one well (instead of ten) is necessary in order to produce the reserves. Reducing the number of required wells from one to ten means that development costs are only five times as large as exploration costs instead of fifty times.

67. The capitalization factor is equal to

$$
\frac{1-e^{-r T}}{r T}
$$

This factor expresses the proportion of value that the taxpayer realizes when forced to capitalize rather than expense a cost.

68. See infra Table XIX (last number in column four, under "Capitalize Development Costs").

69. If the project fails, the taxpayer expenses the rest of the basis, and there is no penalty for having expensed the exploration costs earlier.

70. It is the total cost that affects the threshold price. See supra equation preceding note 58 . 


\begin{tabular}{|c|c|c|c|c|c|c|}
\hline \multicolumn{7}{|c|}{$\begin{array}{l}\text { Investment Threshold Price for the Development Option } \\
\text { Various Probabilities of Successful Development } \\
\text { Number of Wells }=1 \\
\text { Well Life }=7 \text { years } \\
\text { External Tax is Cash Flow or None }\end{array}$} \\
\hline \multirow[b]{2}{*}{ Probability } & \multicolumn{3}{|c|}{ expense development costs } & \multicolumn{3}{|c|}{ capitalize development costs } \\
\hline & $\begin{array}{l}\text { expense } \\
\text { exploration } \\
\text { costs }\end{array}$ & $\begin{array}{l}\text { capitalize } \\
\text { exploration } \\
\text { costs }\end{array}$ & $\begin{array}{l}\text { capitalize } \\
\text { exploration } \\
\text { costs with } \\
\text { recapture }\end{array}$ & $\begin{array}{l}\text { expense } \\
\text { exploration } \\
\text { costs }\end{array}$ & $\begin{array}{l}\text { capitalize } \\
\text { exploration } \\
\text { costs }\end{array}$ & $\begin{array}{l}\text { capitalize } \\
\text { exploration } \\
\text { costs with } \\
\text { recapture }\end{array}$ \\
\hline .01 & 16.00 & 13.17 & 16.00 & 16.02 & 13.19 & 16.03 \\
\hline .05 & 16.00 & 13.22 & 16.02 & 16.11 & 13.33 & 16.13 \\
\hline .1 & 16.00 & 13.29 & 16.04 & 16.22 & 13.51 & 16.26 \\
\hline .2 & 16.00 & 13.42 & 16.08 & 16.42 & 13.83 & 16.50 \\
\hline .3 & 16.00 & 13.54 & 16.12 & 16.61 & 14.14 & 16.73 \\
\hline .4 & 16.00 & 13.65 & 16.16 & 16.78 & 14.43 & 16.94 \\
\hline .5 & 16.00 & 13.75 & 16.19 & 16.95 & 14.70 & 17.14 \\
\hline .6 & 16.00 & 13.85 & 16.22 & 17.11 & 14.96 & 17.33 \\
\hline .7 & 16.00 & 13.95 & 16.25 & 17.26 & 15.21 & 17.51 \\
\hline .8 & 16.00 & 14.04 & 16.28 & 17.40 & 15.44 & 17.68 \\
\hline .9 & 16.00 & 14.12 & 16.31 & 17.54 & 15.66 & 17.85 \\
\hline 1.0 & 16.00 & 14.20 & 16.33 & 17.67 & 15.87 & 18.00 \\
\hline
\end{tabular}

It is clear from column four of Table VI that reducing developmental costs relative to exploration costs causes the effects of the recapture penalty to become more prominent. The range in column four of Table VI is $\$ 0.33$ versus only $\$ .03$ in Table $V$. When the probability of development success is greater, the penalty has a bigger impact on the development threshold price.

Comparing column five in Tables V and VI indicates that the effect of capitalizing development costs remains about the same despite the reduction in the relative significance of development costs. This result is not surprising. In column five, exploration costs are already sunk and expensed on the owner's tax accounts. What then matters most is the impact of tax policy per dollar of development costs (the only costs in the picture), and that impact will be independent of the absolute magnitude of those costs.

It is also useful to consider the impact of longer well life. A longer well life means that capitalization that is recovered through cost depletion will provide a smaller tax benefit since the deductions will be spread out over a longer time period and therefore discounted more heavily. As a result, the probability effect should be greater: Low probabilities increase the chance that costs will be expensed upon failure and reduce the chance 
that capitalization with recovery through cost depletion actually will occur. Table VII verifies this reasoning.

\begin{tabular}{|c|c|c|c|c|c|c|}
\hline \multicolumn{7}{|c|}{$\begin{array}{l}\text { Investment Threshold Price for the Development Option } \\
\text { Various Probabilities of Successful Development } \\
\text { Number of Wells }=10 \\
\text { Well Life }=20 \text { years } \\
\text { External Tax is Cash Flow or None }\end{array}$} \\
\hline \multirow[b]{2}{*}{ Probability } & \multicolumn{3}{|c|}{ expense development costs } & \multicolumn{3}{|c|}{ capitalize development costs } \\
\hline & $\begin{array}{c}\text { expense } \\
\text { exploration } \\
\text { costs }\end{array}$ & $\begin{array}{l}\text { capitalize } \\
\text { exploration } \\
\text { costs }\end{array}$ & $\begin{array}{c}\text { capitalize } \\
\text { exploration } \\
\text { costs with } \\
\text { recapture } \\
\end{array}$ & $\begin{array}{l}\text { expense } \\
\text { exploration } \\
\text { costs }\end{array}$ & $\begin{array}{l}\text { capitalize } \\
\text { exploration } \\
\text { costs }\end{array}$ & $\begin{array}{l}\text { capitalize } \\
\text { exploration } \\
\text { costs with } \\
\text { recapture }\end{array}$ \\
\hline .01 & 16.00 & 13.48 & 16.01 & 16.47 & 13.94 & 16.48 \\
\hline .05 & 16.00 & 14.27 & 16.03 & 17.62 & 15.89 & 17.65 \\
\hline .1 & 16.00 & 14.77 & 16.05 & 18.34 & 17.12 & 18.39 \\
\hline .2 & 16.00 & 15.24 & 16.06 & 19.02 & 18.26 & 19.08 \\
\hline .3 & 16.00 & 15.46 & 16.07 & 19.34 & 18.80 & 19.41 \\
\hline .4 & 16.00 & 15.59 & 16.07 & 19.53 & 19.12 & 19.60 \\
\hline .5 & 16.00 & 15.68 & 16.07 & 19.65 & 19.33 & 19.72 \\
\hline .6 & 16.00 & 15.74 & 16.07 & 19.74 & 19.47 & 19.81 \\
\hline .7 & 16.00 & 15.78 & 16.08 & 19.80 & 19.58 & 19.88 \\
\hline .8 & 16.00 & 15.82 & 16.08 & 19.85 & 19.67 & 19.93 \\
\hline .9 & 16.00 & 15.84 & 16.08 & 19.89 & 19.73 & 19.97 \\
\hline 1.0 & 16.00 & 15.87 & 16.08 & 19.92 & 19.79 & 20.00 \\
\hline
\end{tabular}

The computations for Table VII replace the seven-year well life used in computing Table V with a twenty-year well life. All of the columns in Table VII representing capitalization of development or exploratory costs indicate a greater increase in the development threshold price for a given increase in probability than the corresponding columns in Table V.

So far, the results have indicated that capitalizing costs interacts strongly with the probability of project success. Projects with higher probabilities of success are more likely to involve capitalization and therefore end up with significantly higher development threshold prices. The taxpayer is better off engaging in low probability projects that have compensating higher levels of reserves. For these projects, "on average" the taxpayer will be able to expense much of the exploration and development costs by writing off the costs from failed projects despite the fact that the rules call for capitalization. The effects are larger for projects involving longer well lives.

The presumption underlying all of the numerical examples has been that the external tax is a cash flow tax (or equivalently, no tax). If the 
background tax were an accretion tax, the probability effects should still be present. The effects arise because low probabilities of success provide implicit expensing treatment through the ability to deduct the costs of failed projects. These interactions should exist regardless of the background tax or of whether capitalization "fits in" theoretically with that tax.

Table VIII below contains development threshold prices computed under the assumptions of Table $\mathrm{V}$ except that the background tax is an accretion tax instead of a cash flow tax.

\begin{tabular}{|c|c|c|c|c|c|c|}
\hline \multicolumn{7}{|c|}{$\begin{array}{l}\text { Various Probabilities of Successful Development } \\
\text { Number of Wells }=10 \\
\text { Well Life }=7 \text { years } \\
\text { External Tax is Accretion }\end{array}$} \\
\hline \multirow[b]{2}{*}{ Probability } & \multicolumn{3}{|c|}{ expense development costs } & \multicolumn{3}{|c|}{ capitalize development costs } \\
\hline & $\begin{array}{l}\text { expense } \\
\text { exploration } \\
\text { costs }\end{array}$ & $\begin{array}{l}\text { capitalize } \\
\text { exploration } \\
\text { costs }\end{array}$ & $\begin{array}{l}\text { capitalize } \\
\text { exploration } \\
\text { costs with } \\
\text { recapture } \\
\end{array}$ & $\begin{array}{l}\text { expense } \\
\text { exploration } \\
\text { costs }\end{array}$ & $\begin{array}{l}\text { capitalize } \\
\text { exploration } \\
\text { costs }\end{array}$ & $\begin{array}{l}\text { capitalize } \\
\text { exploration } \\
\text { costs with } \\
\text { recapture } \\
\end{array}$ \\
\hline .01 & 17.59 & 14.81 & 17.60 & 17.77 & 14.99 & 17.77 \\
\hline .05 & 17.59 & 15.67 & 17.61 & 18.21 & 16.29 & 18.22 \\
\hline .1 & 17.59 & 16.21 & 17.61 & 18.49 & 17.11 & 18.51 \\
\hline .2 & 17.59 & 16.71 & 17.62 & 18.75 & 17.87 & 18.77 \\
\hline .3 & 17.59 & 16.95 & 17.62 & 18.87 & 18.23 & 18.89 \\
\hline .4 & 17.59 & 17.09 & 17.62 & 18.94 & 18.44 & 18.97 \\
\hline .5 & 17.59 & 17.18 & 17.62 & 18.99 & 18.58 & 19.02 \\
\hline .6 & 17.59 & 17.25 & 17.62 & 19.02 & 18.68 & 19.05 \\
\hline .7 & 17.59 & 17.30 & 17.62 & 19.05 & 18.75 & 19.07 \\
\hline .8 & 17.59 & 17.33 & 17.62 & 19.06 & 18.81 & 19.09 \\
\hline .9 & 17.59 & 17.36 & 17.62 & 19.08 & 18.85 & 19.11 \\
\hline 1.0 & 17.59 & 17.39 & 17.62 & 19.09 & 18.89 & 19.12 \\
\hline
\end{tabular}

Comparing columns three through seven of this table with the corresponding columns in Table $\mathrm{V}$ indicates that capitalization interacts with the probability of successful development in a very similar way: The change in development threshold price per unit of probability is nearly the same with the two different external taxes.

It is interesting to note that almost all of the threshold development prices are higher when the background tax is an accretion tax. The main reason for this phenomenon is that the accretion tax reduces the required after-tax riskless rate, and it is less costly to wait for a higher price prior 
to developing. ${ }^{71}$

A final issue is whether or not projects with low probabilities and high reserves are an important component of the actual pool from which the investor will choose. If not, the fact that capitalization rules create a bias in favor of these projects may not matter much. The following Table indicates the distribution of success probabilities for two categories of projects. One category is the class of projects that the investor will develop immediately after exploration, assuming that the oil price is equal to the exploration threshold price. The second category includes projects that the investor will not develop immediately but will develop if the price rises up to a dollar above the exploration threshold price. This category consists of the explored properties in "inventory" that are closest to development. ${ }^{72}$

\begin{tabular}{|c|c|c|}
\hline \multicolumn{3}{|c|}{$\begin{array}{l}\text { The Distribution of Development Success Probabilities } \\
\text { Tax Regime is Expensing of Exploratory Costs and Capitalization of Development Costs } \\
\text { Exploration Threshold Price is } \$ 8.30 \\
\text { Extemal Tax is Cash Flow or None }\end{array}$} \\
\hline $\begin{array}{c}\text { Prohability } \\
\text { Range }\end{array}$ & $\begin{array}{l}\text { Propontions for Projects } \\
\text { Devcloped Immediately }\end{array}$ & $\begin{array}{l}\text { Proportions for Projects with Development } \\
\text { Threshold Prices hetween } \$ 8.30 \text { and } \$ 9.30\end{array}$ \\
\hline 00.1 & .014 & .020 \\
\hline .10 .2 & .048 & .059 \\
\hline .210 .3 & .073 & .081 \\
\hline 310.4 & .091 & .096 \\
\hline .410 .5 & .106 & .107 \\
\hline .510 .6 & .117 & .116 \\
\hline 610.7 & .127 & .123 \\
\hline .710 .8 & .135 & .128 \\
\hline 8 to. 9 & .142 & .133 \\
\hline .9101 & .148 & .137 \\
\hline
\end{tabular}

71. The "option multiple" is higher when the accretion tax is the background tax. As a result, the ratio of the present value of revenues to expected costs must be higher before proceeding. See supra note 59, and accompanying text.

It is not always the case that the development threshold price is higher when the external tax is an accretion tax than when the external tax is a cash flow tax. See infra column two of Table XIV (for long well lives, development threshold prices are less than $\$ 16$, the value that would apply if the external tax were a cash flow tax). Aside from the option multiple, the development threshold price is directly proportional to

$$
\frac{\delta T}{1-e^{-\delta T}}
$$

See supra equation preceding note 56. This factor is increasing in $\delta T$, and $\delta$ is .0297 when the external tax is a $20 \%$ accretion tax versus .04 when the external tax is a cash flow tax. For long well lives (large $T$ ), the factor will be much smaller when an accretion tax is the external tax (versus a cash flow tax), and therefore may result in a smaller development threshold price despite the larger option multiple that accompanies the external accretion tax.

72. There is no fixed well life, reserve level, or number of wells. The statistics for each category are averages from a random drawing of a very large number of projects in that category. 
The Table indicates that there are very few projects in the lowest probability range. However, there are quite a few projects in the .1 to .5 probability range. Looking back at Tables V, VI, VII, and VIII, it is clear that these projects will enjoy substantially lower development threshold prices than projects with higher development success probabilities. Part IV discusses some additional evidence on the significance of probability effects. $^{73}$

\section{Percentage Depletion Effects}

It is clear from the formula for $P_{2}^{*}$, the development threshold price, that changing the percentage depletion rate affects $P_{2}{ }^{*}$ by a multiplicative factor that is independent of any project characteristics and of other features of the tax regime. ${ }^{74}$ In particular, a change in the percentage depletion rate from $\eta_{1}$ to $\eta_{2}$ will change $P_{2}^{*}$ by the following factor:

$$
\frac{\left(1-s+\eta_{1} s\right)}{\left(1-s+\eta_{2} s\right)} \text {. }
$$

The table below assumes the same project characteristics as Table $\mathrm{V}$ but increases the percentage depletion rate from zero to $221 / 2 \%$. Using $\eta_{1}=$ $0, \eta_{2}=.225$, and the tax rate, $s=.4$, the new threshold prices will be .8696 times as large as the old threshold prices. Table $\mathrm{X}$ displays the new prices that correspond to the old prices in Table V.

It will turn out that percentage depletion changes exploration threshold prices by the same proportion that it changes development threshold prices. ${ }^{75}$ As a result, the effects of percentage depletion are very clear. Adding such an allowance simply lowers exploration and development threshold prices by a proportion that is independent of well characteristics, well costs, and the characteristics of the tax regime other than the percentage depletion rate. There is no reason to give further consideration to percentage depletion, and the remaining results in the article presume no percentage depletion allowance.

\section{Well Life Effects}

Another parameter that may vary is well life. The following table considers a project with a fifty percent chance of success that will require seven wells if successful. The table presents development threshold prices for various well lives. In each case, project reserves adjust so that

73. See infra text accompanying notes $90-91$.

74. See supra equation accompanying note 58 . Holding project characteristics, project costs, and the tax regime other than percentage depletion constant, this equation may be rewritten as:

$$
P_{2}^{*}(1-s+\eta s)=K
$$

where $K$ is a constant, $s$ is the tax rate, and $\eta$ is the percentage depletion rate.

75. See infra equation preceding note 80 . 


\begin{tabular}{|c|c|c|c|c|c|c|}
\hline \multicolumn{7}{|c|}{$\begin{array}{l}\text { Investment Threshold Price for the Development Option } \\
\text { Percentage Depletion at } 221 / 2 \% \text { Rate } \\
\text { Various Probabilities of Successful Development } \\
\text { Number of Wells }=10 \\
\text { Well Life }=7 \text { years } \\
\text { External Tax is Cash Flow or None }\end{array}$} \\
\hline \multirow[b]{2}{*}{ probability } & \multicolumn{3}{|c|}{ expense development costs } & \multicolumn{3}{|c|}{ capitalize development costs } \\
\hline & $\begin{array}{c}\text { expense } \\
\text { exploration } \\
\text { costs }\end{array}$ & $\begin{array}{l}\text { capitalize } \\
\text { exploration } \\
\text { costs }\end{array}$ & $\begin{array}{l}\text { capitalize } \\
\text { exploration } \\
\text { costs with } \\
\text { recapture }\end{array}$ & $\begin{array}{l}\text { expense } \\
\text { exploration } \\
\text { costs }\end{array}$ & $\begin{array}{l}\text { capitalize } \\
\text { exploration } \\
\text { costs }\end{array}$ & $\begin{array}{c}\text { capitalize } \\
\text { exploration } \\
\text { costs with } \\
\text { recapture } \\
\end{array}$ \\
\hline .01 & 13.91 & 11.71 & 13.92 & 14.09 & 11.89 & 14.09 \\
\hline .05 & 13.91 & 12.40 & 13.92 & 14.51 & 12.99 & 14.52 \\
\hline .1 & 13.91 & 12.82 & 13.93 & 14.78 & 13.69 & 14.80 \\
\hline .2 & 13.91 & 13.22 & 13.94 & 15.03 & 14.34 & 15.05 \\
\hline .3 & 13.91 & 13.41 & 13.94 & 15.15 & 14.64 & 15.17 \\
\hline .4 & 13.91 & 13.52 & 13.94 & 15.22 & 14.82 & 15.24 \\
\hline .5 & 13.91 & 13.59 & 13.94 & 15.26 & 14.94 & 15.29 \\
\hline .6 & 13.91 & 13.65 & 13.94 & 15.29 & 15.03 & 15.32 \\
\hline .7 & 13.91 & 13.68 & 13.94 & 15.32 & 15.09 & 15.35 \\
\hline .8 & 13.91 & 13.71 & 13.94 & 15.34 & 15.14 & 15.36 \\
\hline .9 & 13.91 & 13.74 & 13.94 & 15.35 & 15.17 & 15.38 \\
\hline 1.0 & 13.91 & 13.76 & 13.94 & 15.36 & 15.21 & 15.39 \\
\hline
\end{tabular}

the development threshold price would be $\$ 16$ per barrel in the absence of taxes. 


\begin{tabular}{|c|c|c|c|c|c|c|}
\hline \multicolumn{7}{|c|}{$\begin{array}{c}\text { Investment Threshold Price for the Development Option } \\
\text { Various Well Lives } \\
\text { Number of Wells }=7 \\
\text { Probability of Successful Development }=.5 \\
\text { External Tax is Cash Flow or None }\end{array}$} \\
\hline \multirow[b]{2}{*}{ Well Life } & \multicolumn{3}{|c|}{ expense development costs } & \multicolumn{3}{|c|}{ capitalize development costs } \\
\hline & $\begin{array}{l}\text { expense } \\
\text { exploration } \\
\text { costs }\end{array}$ & $\begin{array}{l}\text { capitalize } \\
\text { exploration } \\
\text { costs }\end{array}$ & $\begin{array}{l}\text { capitalize } \\
\text { exploration } \\
\text { costs with } \\
\text { recapture } \\
\end{array}$ & $\begin{array}{l}\text { expense } \\
\text { exploration } \\
\text { costs }\end{array}$ & $\begin{array}{l}\text { capitalize } \\
\text { exploration } \\
\text { costs }\end{array}$ & $\begin{array}{l}\text { capitalize } \\
\text { exploration } \\
\text { costs with } \\
\text { recapture }\end{array}$ \\
\hline 2 & 16.00 & 15.46 & 16.01 & 16.47 & 15.93 & 16.48 \\
\hline 4 & 16.00 & 15.48 & 16.03 & 16.90 & 16.38 & 16.93 \\
\hline 6 & 16.00 & 15.49 & 16.04 & 17.31 & 16.80 & 17.35 \\
\hline 8 & 16.00 & 15.50 & 16.05 & 17.69 & 17.19 & 17.74 \\
\hline 10 & 16.00 & 15.51 & 16.06 & 18.05 & 17.56 & 18.11 \\
\hline 12 & 16.00 & 15.52 & 16.07 & 18.39 & 17.91 & 18.46 \\
\hline 15 & 16.00 & 15.53 & 16.08 & 18.86 & 18.39 & 18.94 \\
\hline 20 & 16.00 & 15.55 & 16.10 & 19.54 & 19.10 & 19.65 \\
\hline 25 & 16.00 & 15.57 & 16.12 & 20.14 & 19.70 & 20.25 \\
\hline 30 & 16.00 & 15.58 & 16.13 & 20.64 & 20.23 & 20.78 \\
\hline 35 & 16.00 & 15.59 & 16.15 & 21.09 & 20.68 & 21.23 \\
\hline 40 & 16.00 & 15.61 & 16.16 & 21.47 & 21.07 & 21.63 \\
\hline
\end{tabular}

Columns three, five, and six of the Table XI indicate that capitalization of development or exploration costs results in a bias in favor of projects with shorter well lives. This result is not surprising. The background tax is a cash flow tax, and capitalization of costs over a longer period of time is a bigger disadvantage compared to expensing. The recapture of expensed exploration costs also has a bigger impact for longer well lives (column four). The penalty rate for recapture of expensed exploratory costs is the capitalization rate minus one where the capitalization rate is the present value of capitalizing one dollar of expenses and recovering it through cost depletion. A longer well life means a lower capitalization rate and a larger penalty rate.

These effects are sensitive to the "number of wells" variable. If fewer wells are required, development costs are lower and less important relative to exploration costs. Lower relative development costs will enhance the impact of well life under a policy of capitalizing exploration expenses or under a policy providing for recapture of expensed exploration costs. At the same time, the impact of well life will be lower in cases where development costs are capitalized. The following table (Table XII), when compared to Table XI, illustrates these effects by presenting results as- 
suming that only one well is required to produce the reserves instead of the seven required in the Table XI example.

\begin{tabular}{|c|c|c|c|c|c|c|}
\hline & Invest & $\begin{array}{l}\text { Thresho } \\
\text { Probability } \\
\text { Extern }\end{array}$ & $\begin{array}{l}\text { Table XII } \\
\text { Price for th } \\
\text { rious Well Li } \\
\text { nber of Well } \\
\text { Juccessful D } \\
\text { ax is Cash Fl }\end{array}$ & $\begin{array}{l}\text { evelopmer } \\
\text { opment }=.5 \\
\text { or None }\end{array}$ & Dption & \\
\hline \multirow[b]{2}{*}{ Well Life } & \multicolumn{3}{|c|}{ expense development costs } & \multicolumn{3}{|c|}{ capitalize development costs } \\
\hline & $\begin{array}{l}\text { expense } \\
\text { exploration } \\
\text { costs }\end{array}$ & $\begin{array}{c}\text { capitalize } \\
\text { exploration } \\
\text { costs }\end{array}$ & $\begin{array}{c}\text { capitalize } \\
\text { exploration } \\
\text { costs with } \\
\text { recapture }\end{array}$ & $\begin{array}{l}\text { expense } \\
\text { exploration } \\
\text { costs }\end{array}$ & $\begin{array}{l}\text { capitalize } \\
\text { exploration } \\
\text { costs }\end{array}$ & $\begin{array}{l}\text { capitalize } \\
\text { exploration } \\
\text { costs with } \\
\text { recapture }\end{array}$ \\
\hline 2 & 16.00 & 13.62 & 16.06 & 16.29 & 13.92 & 16.35 \\
\hline 4 & 16.00 & 13.68 & 16.11 & 16.57 & 14.25 & 16.69 \\
\hline 6 & 16.00 & 13.73 & 16.17 & 16.83 & 14.56 & 17.00 \\
\hline 8 & 16.00 & 13.78 & 16.21 & 17.07 & 14.85 & 17.29 \\
\hline 10 & 16.00 & 13.82 & 16.26 & 17.30 & 15.12 & 17.56 \\
\hline 12 & 16.00 & 13.86 & 16.30 & 17.51 & 15.38 & 17.81 \\
\hline 15 & 16.00 & 13.92 & 16.36 & 17.81 & 15.73 & 18.17 \\
\hline 20 & 16.00 & 14.01 & 16.45 & 18.24 & 16.25 & 18.69 \\
\hline 25 & 16.00 & 14.09 & 16.52 & 18.62 & 16.70 & 19.14 \\
\hline 30 & 16.00 & 14.15 & 16.59 & 18.94 & 17.09 & 19.53 \\
\hline 35 & 16.00 & 14.21 & 16.64 & 19.22 & 17.42 & 19.86 \\
\hline 40 & 16.00 & 14.25 & 16.69 & 19.46 & 17.71 & 20.15 \\
\hline
\end{tabular}

Another possible modification of the parameters in Table XI is to change the probability of development success. A lower probability makes it less likely that the taxpayer will face capitalization of costs. The taxpayer will be able to expense development and exploration costs in a greater proportion of cases since the failure rate is higher. A lower probability should therefore mitigate the well life effects that arise from capitalization rules.

The next table (Table XIII), when compared to Table XI, indicates that this reasoning is correct. This new table computes development threshold prices under the same assumptions as Table XI except that the probability of development success is ten percent instead of fifty percent. The increase in development threshold price due to a given increase in well life is lower for all the columns (three through seven) that involve capitalization rules. 


\begin{tabular}{|c|c|c|c|c|c|c|}
\hline \multicolumn{7}{|c|}{$\begin{array}{c}\text { Various Well Lives } \\
\text { Number of Wells }=7 \\
\text { Probability of Successful Development }=.1 \\
\text { External Tax is Cash Flow or None } \\
\end{array}$} \\
\hline \multirow[b]{2}{*}{ Well Life } & \multicolumn{3}{|c|}{ expense development costs } & \multicolumn{3}{|c|}{ capitalize development costs } \\
\hline & $\begin{array}{l}\text { expense } \\
\text { exploration } \\
\text { costs }\end{array}$ & $\begin{array}{l}\text { capitalize } \\
\text { exploration } \\
\text { costs }\end{array}$ & $\begin{array}{l}\text { capitalize } \\
\text { exploration } \\
\text { costs with } \\
\text { recapture }\end{array}$ & $\begin{array}{l}\text { expense } \\
\text { exploration } \\
\text { costs }\end{array}$ & $\begin{array}{l}\text { capitalize } \\
\text { exploration } \\
\text { costs }\end{array}$ & $\begin{array}{l}\text { capitalize } \\
\text { exploration } \\
\text { costs with } \\
\text { recapture }\end{array}$ \\
\hline 2 & 16.00 & 14.46 & 16.01 & 16.26 & 14.72 & 16.27 \\
\hline 4 & 16.00 & 14.46 & 16.01 & 16.51 & 14.97 & 16.52 \\
\hline 6 & 16.00 & 14.47 & 16.02 & 16.74 & 15.21 & 16.76 \\
\hline 8 & 16.00 & 14.48 & 16.03 & 16.95 & 15.43 & 16.98 \\
\hline 10 & 16.00 & 14.48 & 16.03 & 17.16 & 15.64 & 17.19 \\
\hline 12 & 16.00 & 14.49 & 16.04 & 17.35 & 15.83 & 17.39 \\
\hline 15 & 16.00 & 14.49 & 16.05 & 17.61 & 16.10 & 17.66 \\
\hline 20 & 16.00 & 14.51 & 16.06 & 18.00 & 16.50 & 18.05 \\
\hline 25 & 16.00 & 14.52 & 16.07 & 18.33 & 16.85 & 18.40 \\
\hline 30 & 16.00 & 14.52 & 16.07 & 18.62 & 17.14 & 18.69 \\
\hline 35 & 16.00 & 14.53 & 16.08 & 18.87 & 17.40 & 18.95 \\
\hline 40 & 16.00 & 14.54 & 16.09 & 19.08 & 17.62 & 19.17 \\
\hline
\end{tabular}

So far, results have been for the case where the background tax is a cash flow tax. Consider instead a $20 \%$ accretion tax as a background tax. A $20 \%$ accretion tax rate will reduce the riskless rate of return by $20 \%$ compared to the riskless rate in a cash flow world or in a world with no taxes. This reduction means investors will discount future returns at a lower rate. However, the accretion tax also reduces the returns themselves by the same $20 \%$. The two effects cancel out so that value (for projects in the "external" non-oil and gas sector) is independent of the $\operatorname{tax}^{76}$

Since the external accretion tax determines required rates of return, the discount rate in the oil and gas sector also will be $20 \%$ lower. Revenues in the oil and gas sector are subject to cash flow treatment. If the taxpayer can also expense exploration and development costs, then the oil and gas sector will receive pure cash flow treatment. In effect, the government will reduce the taxpayer's investment, and the taxpayer will earn tax-free returns on the remainder. ${ }^{77}$ The reduced discount rate (due to the external, but dominant, accretion tax) will apply to these returns,

76. See supra text accompanying note 10 .

77. See supra note 45 . 
and the taxpayer's project will be worth more than it would be if the external tax were a cash flow tax. The advantage of discounting with a reduced rate will have a greater effect when returns are further in the future. As a result, expensing of costs when the external tax is an accretion tax should favor projects with long well lives.

Column two of the following table (Table XIV) indicates that the effect is quite significant. This column presents threshold prices when rule of expensing all costs applies. Given that revenues receive cash flow treatment, column two represents a pure cash flow tax in the oil and gas sector combined with a pure accretion tax that applies in all other sectors. Moving from the tenth percentile well life of around two years to the ninetieth percentile well life of around twenty years causes a $\$ 1.40$ drop in the threshold development price. Column two in Table XIV is radically different from the same column in Table XI, where the threshold price is constant (and independent of well life) at $\$ 16$ per barrel.

\begin{tabular}{|c|c|c|c|c|c|c|}
\hline \multicolumn{7}{|c|}{$\begin{array}{c}\text { Various Well Lives } \\
\text { Number of Wells }=7 \\
\text { Probability of Successful Development }=.5 \\
\text { External Tax is Accretion } \\
\end{array}$} \\
\hline \multirow[b]{2}{*}{ Well Life } & \multicolumn{3}{|c|}{ expense development costs } & \multicolumn{3}{|c|}{ capitalize development costs } \\
\hline & $\begin{array}{l}\text { expense } \\
\text { exploration } \\
\text { costs }\end{array}$ & $\begin{array}{l}\text { capitalize } \\
\text { exploration } \\
\text { costs }\end{array}$ & $\begin{array}{l}\text { capitalize } \\
\text { exploration } \\
\text { costs with } \\
\text { recapture }\end{array}$ & $\begin{array}{l}\text { expense } \\
\text { exploration } \\
\text { costs }\end{array}$ & $\begin{array}{l}\text { capitalize } \\
\text { exploration } \\
\text { costs }\end{array}$ & $\begin{array}{l}\text { capitalize } \\
\text { exploration } \\
\text { costs with } \\
\text { recapture } \\
\end{array}$ \\
\hline 2 & 18.03 & 17.42 & 18.04 & 18.45 & 17.84 & 18.46 \\
\hline 4 & 17.85 & 17.26 & 17.87 & 18.67 & 18.07 & 18.69 \\
\hline 6 & 17.68 & 17.10 & 17.71 & 18.86 & 18.28 & 18.89 \\
\hline 8 & 17.51 & 16.95 & 17.55 & 19.03 & 18.47 & 19.07 \\
\hline 10 & 17.35 & 16.81 & 17.40 & 19.19 & 18.64 & 19.24 \\
\hline 12 & 17.19 & 16.66 & 17.26 & 19.33 & 18.79 & 19.39 \\
\hline 15 & 16.97 & 16.46 & 17.04 & 19.51 & 18.99 & 19.58 \\
\hline 20 & 16.63 & 16.14 & 16.72 & 19.75 & 19.26 & 19.84 \\
\hline 25 & 16.31 & 15.85 & 16.41 & 19.92 & 19.47 & 20.03 \\
\hline 30 & 16.02 & 15.59 & 16.14 & 20.05 & 19.62 & 20.17 \\
\hline 35 & 15.76 & 15.35 & 15.89 & 20.15 & 19.73 & 20.27 \\
\hline 40 & 15.53 & 15.13 & 15.66 & 20.21 & 19.81 & 20.34 \\
\hline
\end{tabular}

Now consider shifting from expensing treatment for all costs to one of the other five cost treatments in the Table. Such shifts in Table XIV cause almost the same change in development threshold prices as the equivalent shifts in Table XI. Once we have corrected for the overall 
impact of embedding the oil and gas sector in an accretion tax world instead of a cash flow tax world, the relative effects of various policies remain the same.

\section{E. Development Cost Effects}

A final factor to consider is variation in development cost. This cost depends primarily on the number of wells required to recover the reserves. Each extra well adds $\$ 500,000$ in costs so that recovery through one well $(\$ 500,000$ development cost) will be much less costly than through ten wells $(\$ 5,000,000$ development cost). Since exploration cost is fixed at $\$ 100,000$, varying the number of wells also changes the relative role of development and exploration costs.

The next Table presents development threshold prices for a project with a well life of seven years and a fifty percent probability of development success. The number of wells varies, and reserves for each project are set in a compensating manner (more wells, more reserves) so that the development threshold price is $\$ 16$ per barrel in a setting with no taxes.

\begin{tabular}{|c|c|c|c|c|c|c|}
\hline \multicolumn{7}{|c|}{$\begin{array}{l}\text { Investment Threshold Price for the Development Option } \\
\text { Varying Development Cost } \\
\text { Well Life }=7 \text { years } \\
\text { Probability of Successful Development }=.5 \\
\text { External Tax is Cash Flow or None } \\
\end{array}$} \\
\hline \multirow[b]{2}{*}{$\begin{array}{l}\text { Number of } \\
\text { Wells }\end{array}$} & \multicolumn{3}{|c|}{ expense development costs } & \multicolumn{3}{|c|}{ capitalize development costs } \\
\hline & $\begin{array}{l}\text { expense } \\
\text { exploration } \\
\text { costs }\end{array}$ & $\begin{array}{l}\text { capitalize } \\
\text { exploration } \\
\text { costs }\end{array}$ & $\begin{array}{c}\text { capitalize } \\
\text { exploration } \\
\text { costs with } \\
\text { recapture }\end{array}$ & $\begin{array}{l}\text { expense } \\
\text { exploration } \\
\text { costs }\end{array}$ & $\begin{array}{l}\text { capitalize } \\
\text { exploration } \\
\text { costs }\end{array}$ & $\begin{array}{c}\text { capitalize } \\
\text { exploration } \\
\text { costs with } \\
\text { recapture }\end{array}$ \\
\hline 2 & 16.00 & 14.57 & 16.12 & 17.21 & 15.78 & 17.33 \\
\hline 4 & 16.00 & 15.17 & 16.07 & 17.40 & 16.58 & 17.47 \\
\hline 6 & 16.00 & 15.42 & 16.05 & 17.48 & 16.90 & 17.53 \\
\hline 8 & 16.00 & 15.55 & 16.04 & 17.52 & 17.07 & 17.56 \\
\hline 10 & 16.00 & 15.63 & 16.03 & 17.55 & 17.18 & 17.58 \\
\hline 12 & 16.00 & 15.69 & 16.03 & 17.57 & 17.26 & 17.59 \\
\hline 15 & 16.00 & 15.75 & 16.02 & 17.59 & 17.34 & 17.61 \\
\hline 20 & 16.00 & 15.81 & 16.02 & 17.61 & 17.42 & 17.62 \\
\hline 25 & 16.00 & 15.85 & 16.01 & 17.62 & 17.47 & 17.63 \\
\hline 30 & 16.00 & 15.87 & 16.01 & 17.63 & 17.50 & 17.64 \\
\hline 35 & 16.00 & 15.89 & 16.01 & 17.63 & 17.52 & 17.64 \\
\hline 40 & 16.00 & 15.90 & 16.01 & 17.64 & 17.54 & 17.64 \\
\hline
\end{tabular}


It is easy to explain the pattern in the table. In column three, the threshold prices increase along with the number of wells, almost reaching the $\$ 16$ per barrel no-tax figure. This column represents a policy of capitalizing only exploration costs. Capitalizing exploration costs results in a "tax bonus" at the development stage that lowers the after-tax cost of development. ${ }^{78}$ A lower development cost implies a lower development threshold price than the $\$ 16$ no-tax price. As the number of wells increases, exploration cost becomes negligible relative to development cost and total cost. As a result, the fact that taxpayers receive a tax bonus in the form of being able to capitalize (already sunk) exploration costs does not have very much impact.

Capitalization of development costs causes the development threshold price to increase with the number of wells for different reasons. Consider column five of the table. The prices in this column are higher than those in column two since capitalizing (versus expensing) development costs increases after-tax cost so that investors will require higher oil prices before developing. The relative impact of capitalizing development costs increases with the number of wells since an increase in the number of wells increases the relative share of development cost in total cost. The range of increase in column five is rather small because development costs are a large proportion of total cost to begin with.

The recapture penalty increases after-tax development cost, and therefore also increases development threshold prices: The prices in column four are all larger than the no-tax price of $\$ 16$. The impact of the recapture penalty falls off with the required number of wells, since the penalty, along with exploration costs, becomes increasingly overshadowed by the increased development costs that result from the larger number of wells.

None of the reasoning that explains the results in Table XV involves the timing of costs. As a result, one would expect the same pattern of development cost effects to occur if the external tax is an accretion tax instead of a cash flow tax. The next table (Table XVI) verifies that conclusion. The prices in the table are computed using the same assumptions as in Table XV except that an accretion tax is the external tax instead of a cash flow tax.

Switching the external tax to an accretion tax increases the threshold development price for the case of expensing all costs to $\$ 17.59$ from $\$ 16$. Otherwise, the patterns in Table XVI are identical to the ones found in Table XV.

78. The taxpayer incurred the costs earlier, at the exploration stage. Proceeding with development means that the taxpayer will begin receiving the tax benefits associated with the exploration costs without paying any such costs currently. 


\begin{tabular}{|c|c|c|c|c|c|c|}
\hline \multicolumn{7}{|c|}{$\begin{array}{c}\text { Varying Development Costs } \\
\text { Well Life }=7 \text { years } \\
\text { Probability of Successful Development }=.5 \\
\text { External Tax is Accretion }\end{array}$} \\
\hline \multirow{2}{*}{$\begin{array}{l}\text { Number of } \\
\text { Wells }\end{array}$} & \multicolumn{3}{|c|}{ expense development costs } & \multicolumn{3}{|c|}{ capitalize development costs } \\
\hline & $\begin{array}{l}\text { expense } \\
\text { exploration } \\
\text { costs }\end{array}$ & $\begin{array}{l}\text { capitalize } \\
\text { exploration } \\
\text { costs }\end{array}$ & $\begin{array}{l}\text { capitalize } \\
\text { exploration } \\
\text { costs with } \\
\text { recapture } \\
\end{array}$ & $\begin{array}{l}\text { expense } \\
\text { exploration } \\
\text { costs }\end{array}$ & $\begin{array}{l}\text { capitalize } \\
\text { exploration } \\
\text { costs }\end{array}$ & $\begin{array}{l}\text { capitalize } \\
\text { exploration } \\
\text { costs with } \\
\text { recapture } \\
\end{array}$ \\
\hline 2 & 17.59 & 16.00 & 17.70 & 18.68 & 17.09 & 18.79 \\
\hline 4 & 17.59 & 16.67 & 17.66 & 18.86 & 17.93 & 18.92 \\
\hline 6 & 17.59 & 16.94 & 17.64 & 18.93 & 18.27 & 18.97 \\
\hline 8 & 17.59 & 17.09 & 17.63 & 18.96 & 18.46 & 19.00 \\
\hline 10 & 17.59 & 17.18 & 17.62 & 18.99 & 18.58 & 19.02 \\
\hline 12 & 17.59 & 17.25 & 17.62 & 19.00 & 18.66 & 19.03 \\
\hline 15 & 17.59 & 17.31 & 17.61 & 19.02 & 18.74 & 19.04 \\
\hline 20 & 17.59 & 17.38 & 17.61 & 19.04 & 18.83 & 19.05 \\
\hline 25 & 17.59 & 17.42 & 17.60 & 19.05 & 18.88 & 19.06 \\
\hline 30 & 17.59 & 17.45 & 17.60 & 19.06 & 18.91 & 19.07 \\
\hline 35 & 17.59 & 17.47 & 17.60 & 19.06 & 18.94 & 19.07 \\
\hline 40 & 17.59 & 17.49 & 17.60 & 19.06 & 18.96 & 19.07 \\
\hline
\end{tabular}

\section{TAXES AND THE EXPLORATION OPTION}

Computing threshold prices for the exploration option is more difficult than computing such prices for the development option. Exercising the development option meant that the investor also would execute the ensuing production option. ${ }^{79}$ In contrast, exercising the exploration option means paying a certain amount of money to draw a development option at random. If the development project is good enough, the investor will proceed to development (and production). However, bad draws will go into an inventory of explored, but undeveloped, properties.

There will be some investment threshold price, $P_{1}^{*}$, for the exploration option. If the oil price is above $P_{1}^{*}$, exploration will proceed. Every time the investor explores a property, the result will be a potential development project, characterized by $R$ (recoverable reserves), $N$ (number of wells required), $T$ (time required to recover), and $Q$ (probability of development success). For each development project, there will be a development threshold price, $P_{2}^{*}$. If $P_{1}{ }^{*}>P_{2}^{*}$, then the investor will immediately

79. See supra text accompanying notes 47-51. 
develop the prospect. On the other hand, if $P_{1}{ }^{*}<P_{2}{ }^{*}$ and the current oil price is $P_{1}^{*}$, the investor will delay development until prices are higher.

The equation for the development threshold price, $P_{2}^{*}$, was a simple formula expressing that price as a function of known parameters like $R$, $N, Q, T$, and the costs of exploration and development. The situation is not as straightforward for the exploration threshold price, $P_{1}{ }^{*}$. This price will depend on the averages of parameters $R, N, Q$, and $T$, conditional on immediate development. "Conditional on immediate development" means that we consider the average only over the pool of all projects that the investor would develop immediately given a current oil price of $P_{1}{ }^{*}$. We express this conditional average by the notation $E_{M}($.$) . Thus, E_{M}(R)$ means the average reserves over all projects that the investor would develop immediately. Since projects that are worth developing early will tend to be particularly good projects, $E_{M}(R)$ will tend to be larger than the average value of reserves for all possible projects.

Note that the conditional averages assume that $P_{1}^{*}$ is the current price. Thus, computing these averages requires knowing $P_{1}^{*}$. This makes life difficult since the equation for $P_{1}{ }^{*}$ itself depends on the averages. We have to solve for $P_{1}^{*}$ and the averages simultaneously.

The equation for $P_{1}^{*}$ also depends on the probability that an exploration draw will result in immediate development given that the current price of oil is $P_{1}^{*}$. Call this probability " $\operatorname{Pr}(M)$." Where " $E_{M}\{$.$\} " means$ "take the conditional average of the expression inside the curly brackets," the equation for $P_{1}{ }^{*}$ is:

$$
\left[\begin{array}{c}
\frac{\beta_{1}-1}{\beta_{l}} P_{I}^{*} E_{M}\left\{Q R \frac{1-e-\delta T}{\delta T}\right\}(1-s+\eta s) \\
-(1-s) I_{d} E_{M}\left\{Q N\left(\left(1-c_{d}\right)+c_{d} \frac{1-e^{-r T}}{r T}\right)\right\} \\
+s I_{e} E_{M}\left\{Q\left(c_{r}\left(\frac{1-e^{-r T}}{r T}-1\right)+c_{e}\left(\frac{1-e^{-r T}}{r T}\right)\right)\right\} \\
-\left(I_{t}(1-s)-s c_{e} I_{e}\right) E_{M}\{(1-Q)\} \\
-I_{e}\left(1-s\left(1-c_{e}\right)\right) \\
=0
\end{array}\right] x r(M)
$$


Except for the conditional average operator, $E_{M}\{$.$\} , the expression in$ big square brackets is familiar. It is very similar to the net present value of a development project. ${ }^{80}$ The last three terms are the appropriate cost terms. The first term is the present value of revenues multiplied by $\left(\beta_{1}-1\right) / \beta_{1}$, the inverse of the "option multiple" that applies to the project. The option multiple increases with the volatility of oil prices and is greater than or equal to one. ${ }^{81}$ The multiplicative factor $\left(\beta_{1}-1\right) / \beta_{1}$ will be less than or equal to one, reflecting the fact that the present value of revenues must exceed costs by the option multiple for development to proceed. The $E_{M}\{$.$\} operators reflect the fact that we are taking the aver-$ age of the expression in square brackets (without the operators) conditional on immediate development. As such, we will be taking averages of positive terms, and the term in square brackets is the average net present value (after reducing revenues by the inverse of the option multiple) in excess of the amount needed to trigger immediate development. ${ }^{82}$ This "average surplus" in square brackets will be less than the average net present value conditional on immediate development. ${ }^{83}$

The term in square brackets is multiplied by $\operatorname{Pr}(M)$, the probability of drawing a project that an investor will develop immediately. Since the average surplus represented in the square brackets is an average conditional on immediate development, the square bracket term times $\operatorname{Pr}(M)$ represents the expected surplus from exploring a property. At the price $P_{1}^{*}$, this expected surplus must be exactly equal to the cost of exploring a property. Subtracting this cost, $I_{e}\left[1-s\left(1-c_{\mathrm{e}}\right)\right]$, must yield zero if we plug in $P_{1}^{*}$. At lower prices, the expected gain will be smaller, and exploration will not be worthwhile. ${ }^{84}$

\section{A. Investment Threshold Prices}

Table XVII below presents exploration threshold prices for the six tax scenarios under consideration. The computations for this table assume that the external tax is a cash flow tax.

80. See supra equation preceding note 58 and accompanying text.

81. See supra note 59 .

82. At the development threshold price, the expected present value of revenues is equal to the option multiple times expected costs. See supra text accompanying note 58. That is, the term in square brackets (without the expectation operators present) would be zero at this price. We are averaging over all cases where the exploration threshold price is greater than the development threshold price. At that higher price, the expression in square brackets (without the expectation operators) will be greater than zero.

83. The reason for the difference is that immediate development means giving up the option to develop later. The expected net present value stemming from immediate development needs to be reduced by the value of that option to have a true measure of surplus.

84. Since $\operatorname{Pr}(M)$ and the averages conditional on development depend on $P_{1}^{*}$, actually computing $P_{1}^{*}$ is complicated. See infra text accompanying notes 109-11. 


\begin{tabular}{|c|c|c|}
\hline \multicolumn{3}{|c|}{$\begin{array}{l}\text { reshold Prices for the Ex } \\
\text { (in dollars per barrel) }\end{array}$} \\
\hline & expense development costs & capitalize development costs \\
\hline expense exploration costs & 7.81 & 8.30 \\
\hline capitalize exploration costs & 9.11 & 9.69 \\
\hline $\begin{array}{c}\text { expense exploration costs } \\
\text { with recapture }\end{array}$ & 7.83 & 8.31 \\
\hline
\end{tabular}

The most striking result in the Table is the large effect that arises from capitalizing exploration costs. This policy increases the exploration threshold price by $\$ 1.30$ which represents an increase of about one-sixth over the no-tax value of that price. The size of the effect is not entirely surprising. Capitalizing exploration costs increases the immediate aftertax cost of exploration substantially, from $\$ 60,000$ per property to $\$ 100,000$ per property. Furthermore, under a policy of capitalization of exploration costs and a current oil price equal to the threshold price, the investor will develop only about nine percent of explored properties immediately. The ability to recover exploration costs for the other projects is put off into the indefinite future. Increased cost means that investors will require higher prices before engaging in exploration.

An earlier Section mentions an important caveat with respect to the apparently large impact of capitalizing exploration expenses on the exploration threshold price. The computed prices do not take into account the ability of the taxpayer to realize losses on low-value properties right after exploration, and later on if prices fall. ${ }^{85}$ About fifty-nine percent of explored properties will be worth less than the $\$ 100,000$ exploration cost given an oil price equal to the exploration threshold. The average loss for properties in this class will be around $\$ 83,000$. In addition, properties initially worth more than $\$ 100,000$ may decline below $\$ 100,000$ in value, permitting losses that represent a portion of the exploration cost to be taken prior to the time that this cost is deducted under the capitalization scheme. The total value of the ability to take losses may eliminate as much as eighty percent of the gap between the threshold price for the case of capitalizing exploration costs and the case of expensing. ${ }^{86}$ As a result, loss-taking is a potentially important phenomenon. A capitaliza-

85. See supra text accompanying notes $52-54$.

86. Computing the impact of loss-taking precisely in the model is very difficult. The eighty percent estimate is an upper bound for the actual number. This estimate is based on the (unrealistic) assumption that there are no transactions costs for trading properties and consists of three elements. First, there are immediate tax losses from properties worth less than $\$ 100,000$ right after exploration is completed. Second, there is the value of the tax timing option for taking further losses on these properties in the future. Third, there is a 
tion rule may be largely ineffective and may induce significant social waste as parties commit resources to completing transactions that are solely motivated by taking tax losses.

Capitalizing development costs increases the exploratory threshold price by about $\$ 0.50$, or about six percent of the no-tax price of $\$ 7.81$. Increasing after-tax development cost diminishes the value of the development option for explored properties but has no effect on the cost of exploration. As a result, taxpayers will require higher oil prices in order to offset the higher after-tax development cost with an increase in the potential benefits of development. ${ }^{87}$

Finally, Table XVII indicates that the recapture of expensed exploratory costs has little impact on the exploration threshold price. The main reason for this result is the same reason that explained the dearth of recapture penalty effects in other contexts: The recapture penalty is small compared to the other components of development cost.

The next table (Table XVIII) indicates the impact on exploration threshold prices of switching the external tax from a cash flow tax to an accretion tax. ${ }^{88}$ The main change is that all the prices are higher by about $\$ 0.80$ or so. As discussed earlier, shifting the external tax to an accretion tax from a cash flow tax reduces the after-tax discount rate in the oil and gas sector. As a result, the potential rewards of waiting for higher prices are greater, and threshold prices will be larger. ${ }^{89}$ The relationships between different tax policies remain about the same as in the case where the external tax is a cash flow tax.

similar valuable tax timing option for properties worth more than $\$ 100,000$ immediately after exploration.

To compute the value of the tax timing option, I used a variant of a standard formula developed for equities. This variant implicitly assumes that there is no event, other than taking tax losses, that will induce the holder to dispose of the property. However, in the model here, if the oil price rises high enough, the holder will exercise the development option, cutting off potential future loss taking. Since these potential losses contribute to the value of the tax timing option, using the variant overestimates the value of the tax timing option. Unfortunately, incorporating the possibility of development into the tax timing option formula would be very difficult, and I leave that project to future research.

The Appendix describes the computation of the estimate in greater detail.

87. Recall that the equation for determining the exploration threshold price pits the excess benefits from development projects that will commence immediately against exploratory costs. See supra the equation preceding note 80 and accompanying text. Increasing development costs reduces the excess benefits, while an increase in the oil price increases these benefits.

88. The figures in Tables XVIII are less accurate than the figures in Table XVII. The program used to compute the Table XVII figures is twice as sensitive to errors. The figures in Table XVIII are still accurate to a few pennies.

89. For a more complete discussion of the impact of an accretion tax in the outside sectors, see supra note 71 and accompanying text. 


\begin{tabular}{|c|c|c|}
\hline \multicolumn{3}{|c|}{$\begin{array}{l}\text { Investment Threshold Prices for the Exploration Option } \\
\text { (in dollars per barrel) } \\
\text { Special Case: Accretion Tax as External Tax } \\
\text { No-Tax Threshold Price is } 7.81\end{array}$} \\
\hline & expense development costs & capitalize development costs \\
\hline expense exploration costs & 8.61 & 9.02 \\
\hline capitalize exploration costs & 9.99 & 10.50 \\
\hline $\begin{array}{l}\text { expense exploration costs } \\
\text { with recapture }\end{array}$ & 8.54 & 9.04 \\
\hline
\end{tabular}

\section{B. Opportunity Set EfFects}

In Part III, many of the tax policies were not neutral with respect to development projects that differ in probability of success, level of development cost, or well life. The Monte Carlo approach used to compute exploration threshold prices also permits an examination of the nature of the projects executed immediately as opposed to those placed in "inventory" for later execution.

The next two tables compile statistics conditional on immediate development and conditional on delayed development respectively. The six main statistics are the mean probability of success, mean reserves, the mean number of wells (mean development costs), the mean well life, the mean "delta factor," and the mean "capitalization factor." The "delta factor" is the present value of a dollar of revenue flow during the life of the well. This factor uses the required after-tax "dividend" rate as the discount rate. The capitalization factor is the present value (in terms of an immediate deduction) of each dollar of costs that are capitalized. The tables display conditional values of these statistics for three separate tax scenarios: expensing of all costs, capitalization of development costs combined with expensing of exploration costs, and expensing of development costs combined with capitalization of exploration costs. Each table also states the exploration threshold price and the probability of immediate development for each separate tax policy. Finally, each table includes unconditional means for purposes of comparison. These unconditional means follow directly from the distributions assumed for the various project characteristics.

The first table (Table XIX) contains statistics conditional on immediate development. Projects developed immediately after exploration will tend to have a higher probability of success, higher reserves, a smaller number of required wells, and a shorter well life (with higher delta and capitalization factors as a result). This tendency is evident from comparing the 
conditional means in the table (columns three, four and five) with the unconditional means in column two.

Of greater interest is any possible distortions in the set of projects developed immediately that result from tax policy. The table assumes a cash flow tax in the external sectors. As a result, column three, expensing of all costs, represents a "neutral" tax policy that will leave the immediate development set the same as without any taxes. This column thus serves as a benchmark for examining the last two columns.

\begin{tabular}{|c|c|c|c|c|}
\hline \multicolumn{5}{|c|}{$\begin{array}{l}\text { Table XIX } \\
\text { Statistics Conditional on Immediate Development } \\
\text { Means with Standard Deviations in Parentheses } \\
\text { Three Tax Scenarios } \\
\text { (1) Expense Exploration and Development Costs } \\
\text { (2) Expense Exploration Costs, Capitalize Development Costs } \\
\text { (3) Capitalize Exploration Costs, Expense Development Costs }\end{array}$} \\
\hline & \multirow{2}{*}{$\begin{array}{l}\text { Unconditional } \\
\text { Statistics } \\
\text { (for reference) }\end{array}$} & \multicolumn{3}{|c|}{ Statistics Conditional on Immediate Development } \\
\hline & & $\begin{array}{c}\text { Expense } \\
\text { All Costs } \\
\mathrm{P}_{1}^{*}=7.81 \\
\operatorname{Prob}(\mathrm{M})=.059\end{array}$ & $\begin{array}{c}\text { Capitalize } \\
\text { Development } \\
\text { Costs } \\
\mathrm{P}_{1}^{*}=8.30 \\
\operatorname{Prob}(\mathrm{M})=.056\end{array}$ & $\begin{array}{c}\text { Capitalize } \\
\text { Exploration } \\
\text { Costs } \\
\mathrm{P}_{1}^{*}=9.11 \\
\text { Prob }(\mathrm{M})=.091\end{array}$ \\
\hline $\begin{array}{c}\text { Mean Probability } \\
\text { of Success }\end{array}$ & 0.5 & $\begin{array}{c}0.6203 \\
(0.0001) \\
\end{array}$ & $\begin{array}{c}0.6161 \\
(0.0001) \\
\end{array}$ & $\begin{array}{c}0.6064 \\
(0.0001) \\
\end{array}$ \\
\hline Mean Reserves & $1,000,000$ & $\begin{array}{c}3,087,276 \\
(1652) \\
\end{array}$ & $\begin{array}{c}3,082,803 \\
(1647) \\
\end{array}$ & $\begin{array}{c}2,722,550 \\
(890) \\
\end{array}$ \\
\hline $\begin{array}{c}\text { Mean Number } \\
\text { of Wells }\end{array}$ & 14.75 & $\begin{array}{r}12.5288 \\
(0.0072) \\
\end{array}$ & $\begin{array}{r}12.3852 \\
(0.0071) \\
\end{array}$ & $\begin{array}{r}12.5947 \\
(0.0044) \\
\end{array}$ \\
\hline Mean Well Life & 9.369 & $\begin{array}{c}7.2852 \\
(0.0025) \\
\end{array}$ & $\begin{array}{c}6.5648 \\
(0.0022) \\
\end{array}$ & $\begin{array}{c}7.4222 \\
(0.0015) \\
\end{array}$ \\
\hline $\begin{array}{c}\text { Mean Delta } \\
\text { Factor }\end{array}$ & 0.843 & $\begin{array}{c}0.87368 \\
(0.00004) \\
\end{array}$ & $\begin{array}{r}0.88432 \\
(0.00003) \\
\end{array}$ & $\begin{array}{c}0.87172 \\
(0.00002) \\
\end{array}$ \\
\hline $\begin{array}{l}\text { Capitalization } \\
\text { Factor Mean }\end{array}$ & 0.812 & $\begin{array}{c}0.84710 \\
(0.00004) \\
\end{array}$ & $\begin{array}{c}0.85952 \\
(0.00004) \\
\end{array}$ & $\begin{array}{c}0.84482 \\
(0.00002) \\
\end{array}$ \\
\hline
\end{tabular}

It is important to consider the probability of immediate development when one compares columns. When this probability is higher, it means that immediate development extends deeper into the pool of possible projects. Since the best projects are done first, going deeper into the pool should cause a drop in the average probability of success, a drop in mean reserves, an increase in mean number of wells, and an increase in mean well life for the class of projects developed immediately.

The results in Part III suggest that capitalizing development costs (but not exploration costs) should cause a shift to lower probability projects, projects with fewer wells, and projects with shorter well life. All three of the expected effects are evident in the table. Mean well life is significantly lower than in the benchmark case, the mean number of wells is 
significantly lower, and the mean probability of success is significantly lower.

It is important to consider whether these effects occur because the probability of immediate development is somewhat higher for the benchmark case $(5.9 \%)$ versus the case of capitalization of development costs $(5.6 \%) .{ }^{90}$ This difference suggests a lower mean well life, a lower mean number of wells, and a higher probability of successful development in the case of capitalization of development costs. This predicted pattern strengthens the case for a probability effect since the probability of successful development is in fact lower than in the benchmark case. Furthermore, the drop in the mean well life is so large that it cannot be explained by the very small $(.3 \%)$ difference in the probability of immediate development.91 Although the decline in the number of wells is quite a bit smaller, it is unlikely that it is caused entirely by going deeper into the pool. ${ }^{92}$

90. It is interesting to note that this lower probability of immediate development $(\operatorname{Pr}(M))$ in the case of capitalizing development costs versus the benchmark case occurs even though the execution threshold price is lower $(\$ 7.81$ versus $\$ 8.30)$ in the benchmark case. Normally, a higher oil price means that it will be optimal to immediately develop a larger proportion of the class of all possible development projects. However, capitalizing development costs increases the development threshold price for most projects, and this effect outweighs the effect of the higher oil price. See supra Tables V-VIII and X-XVI (columns five through seven in these tables cover cases where the taxpayer capitalizes development costs; the development threshold prices in these columns are higher than the prices in the corresponding columns, two through four, for cases where the taxpayer expenses development costs; the differences often are substantial).

91. To prove this point, suppose that the change in mean well life from 6.56 to 7.29 years is due entirely to going deeper into the pool: $5.9 \%$ instead of $5.6 \%$. This assumption means that the "added" projects must have a mean well life of $Y$ divided by 0.3 where:

$$
\begin{gathered}
\frac{X}{5.6}=6.56 \\
\text { and } \frac{X+Y}{5.9}=7.29
\end{gathered}
$$

Solving these equations yields 6.275 for $Y$. As a result, the added projects must have a mean well life of 20.91 . This figure is way above the mean well life (9.82) for the remaining pool, see infra Table XX, and would indicate that the investor is choosing inferior projects.

92. Using the same analysis as in the previous footnote, assume that the change is entirely due to going deeper in the pool in the benchmark case. This assumption requires that the average number of wells for the "added" projects must be $Y$ divided by 0.3 where

$$
\begin{gathered}
\frac{X}{5.6}=12.39 \\
\text { and } \quad \frac{X+Y}{5.9}=12.53 .
\end{gathered}
$$

Solving these equations yields 4.543 for $Y$. As a result, the added projects must require 15.14 wells on average. This figure is significantly above the mean number of wells per 
The final column in Table XIX represents statistics for the case of capitalizing exploration costs. In this case, the probability of immediate development is very much higher than in the benchmark case- $9.1 \%$ versus $5.9 \%$. This difference follows from two phenomena. First, the exploration threshold price is $\$ 1.30$ higher $(\$ 9.11$ versus $\$ 7.81$ ) in the case of capitalization of exploration costs. A higher oil price increases the proportion of projects that an investor would want to develop immediately. Second, capitalizing exploration costs tend to decrease the development threshold price for each project, ${ }^{93}$ so that an investor will want to develop a larger proportion of projects immediately at any given oil price. It appears that most of the effect stems from the first factor, the increase in the exploration threshold price. ${ }^{94}$

The results in Part III suggest that capitalizing exploration costs should lower the probability of successful development, lower mean well life, and lower the mean number of wells for the class of projects developed immediately. Unfortunately, it is not possible to detect any of these effects based on the outcomes in column four of Table XIX. Mean well life and the number of wells increase versus the benchmark case, but these increases may be due to going much deeper into the pool. There is a substantial and significant drop in the probability of development success, but this drop also may be largely or entirely due to going deeper into the pool.

The next table presents statistics for the class of projects for which an investor will delay development given an oil price equal to the exploration threshold price in each tax scenario. To some degree, the statistics may reflect the tax-induced changes in the class of projects taken out of the pool via immediate development. However, it is hard to separate out the tax effects from the impact of different probabilities of immediate development. For example, the mean probability of development success is higher for the case of capitalization of development costs than the benchmark case. This outcome is consistent with the predicted tax effect: the investor will develop more low probability projects immediately, leaving higher probability projects in the pool. But the outcome may also be due to the fact that the investor goes deeper into the pool $(5.9 \%$ versus

project (14.89) for the remaining pool, see infra Table XX, and would indicate that the investor is choosing inferior projects.

93. See supra Tables V-VIII and X-XVI (in each table, the threshold prices in column three, representing a policy of capitalizing exploration costs, are lower than the no-tax threshold prices in column two).

94. An increase of one dollar in the oil price from the $\$ 9.11$ exploration threshold price will cause an investor to develop an additional $2.166 \%$ of all potential projects. Multiplying this $2.166 \%$ by 1.3 yields about $2.8 \%$, most of the $3.1 \%$ gap between the $9.1 \%$ probability of immediate development in the case where investors must capitalize exploration costs and the $5.9 \%$ probability in the benchmark case. In addition, the drop in the development threshold price due to capitalizing exploration costs usually is less than $\$ 0.50$. See supra Table V (compare columns two and three; most projects have high success probabilities; for a success probability of .4 or more, the drop is less than $\$ 0.50$ ), $\$ 0.50$ is much smaller than the $\$ 1.30$ shift in the exploration threshold price. 


\begin{tabular}{|c|c|c|c|c|}
\hline \multicolumn{5}{|c|}{$\begin{array}{l}\text { Table XX } \\
\text { Statistics Conditional on Delayed Development } \\
\text { Means with Standard Deviations in Parentheses } \\
\text { Three Tax Scenarios } \\
\text { (1) Expense Exploration and Development Costs } \\
\text { (2) Expense Exploration Costs, Capitalize Development Costs } \\
\text { (3) Capitalize Exploration Costs, Expense Development Costs }\end{array}$} \\
\hline & \multirow{2}{*}{$\begin{array}{l}\text { Unconditional } \\
\text { Statistics } \\
\text { (for reference) }\end{array}$} & \multicolumn{3}{|c|}{ Statistics Conditional on Immediate Development } \\
\hline & & $\begin{array}{c}\text { Expense } \\
\text { All Costs } \\
\mathrm{P}_{1}^{*}=7.81 \\
\operatorname{Prob}(\mathrm{M})=.059\end{array}$ & $\begin{array}{c}\text { Capitalize } \\
\text { Development } \\
\text { Costs } \\
P_{1}^{*}=8.30 \\
\text { Prob }(M)=.056 \\
\end{array}$ & $\begin{array}{c}\text { Capitalize } \\
\text { Exploration } \\
\text { Costs } \\
\mathrm{P}_{1}^{*}=9.11 \\
\text { Prob(M) }=.091 \\
\end{array}$ \\
\hline $\begin{array}{c}\text { Mean Probability } \\
\text { of Success }\end{array}$ & 0.5 & $\begin{array}{c}0.49242 \\
(0.00003) \\
\end{array}$ & $\begin{array}{c}0.49314 \\
(0.00003) \\
\end{array}$ & $\begin{array}{c}0.48929 \\
(0.00002) \\
\end{array}$ \\
\hline Mean Reserves & $1,000,000$ & $\begin{array}{c}868,967 \\
(226) \\
\end{array}$ & $\begin{array}{c}877,527 \\
(220) \\
\end{array}$ & $\begin{array}{c}826,749 \\
(160) \\
\end{array}$ \\
\hline $\begin{array}{c}\text { Mean Number } \\
\text { of Wells }\end{array}$ & 14.75 & $\begin{array}{l}14.8904 \\
(0.0051) \\
\end{array}$ & $\begin{array}{l}14.8885 \\
(0.0048) \\
\end{array}$ & $\begin{array}{l}14.9659 \\
(0.0037) \\
\end{array}$ \\
\hline Mean Well Life & 9.369 & $\begin{array}{c}9.7870 \\
(0.0010) \\
\end{array}$ & $\begin{array}{c}9.8199 \\
(0.0009) \\
\end{array}$ & $\begin{array}{c}9.8626 \\
(0.0008) \\
\end{array}$ \\
\hline $\begin{array}{l}\text { Mean Delta } \\
\text { Factor }\end{array}$ & 0.843 & $\begin{array}{c}0.84107 \\
(0.00001) \\
\end{array}$ & $\begin{array}{c}0.84057 \\
(0.00001) \\
\end{array}$ & $\begin{array}{c}0.84011 \\
(0.00001) \\
\end{array}$ \\
\hline $\begin{array}{l}\text { Capitalization } \\
\text { Factor Mean }\end{array}$ & 0.812 & $\begin{array}{c}0.80981 \\
(0.00001) \\
\end{array}$ & $\begin{array}{c}0.80922 \\
(0.00001) \\
\end{array}$ & $\begin{array}{c}0.80871 \\
(0.00001) \\
\end{array}$ \\
\hline
\end{tabular}

$5.6 \%$ ) in the benchmark case, so that the remaining projects should have a lower probability on average.

The lack of discriminatory power with respect to the statistics for delayed projects is due to the fact that the investor will develop only a small proportion of the total pool of projects immediately-around $6 \%$ for the benchmark case. The great mass of projects in the delayed group will have development threshold prices much higher than the exploration threshold prices used to delineate the immediate development borderline, regardless of the tax policy that applies. This great mass of projects dominates the determination of the means in Table XX, and drowns out effects that depend on the peculiar traits of the much smaller group of projects removed from the pool.

One method to address this problem would be to examine the traits of the some subset of delayed projects likely to be developed soon. For instance, one might compute statistics for projects that would be developed if the oil price increases one dollar above the exploration threshold price. $^{95}$ Nonetheless, computing such statistics does not seem worth-

95. Part III used exactly this approach to examine the frequency of low probability projects in the set consisting of delayed projects that are the strongest candidates for early development. See supra text accompanying note 72 . 
while. The outcomes in Table XIX indicate significant tax effects for the pool of projects developed immediately, at least for the case of capitalizing development costs. One would expect to see the same pattern of effects for the set of projects in the delayed pool that the investor would develop next.

\section{SUMMARY AND CONCLUSIONS}

Oil and gas projects consist of a series of options. The mineral owner must first decide whether to spend money on "exploration" in order to learn the extent of potential reserves, the cost and timing of recovering the reserves, and the probability that the reserves are actually recoverable. The mineral owner holds an "exploration option" since the owner need not explore immediately but may wait until an increase in mineral prices makes the potential rewards from exploration more promising.

After exploration of a property, the owner holds a "development option." The owner may pay to drill a test well to see if the reserves are recoverable, or the owner may put off any such test until prices are higher. If the test well proves there are recoverable reserves, the owner has a "production option." This option consists of the ability to complete the test well as a producer, and to drill and complete any other wells required to completely drain the recoverable reserves.

The incentives for exploration, development, and production depend on the "threshold prices" at which an investor will execute each option. One way to examine the impact of tax policy is to determine how various policies affect threshold prices. This article looks primarily at the impact on exploration and development threshold prices, using a simplified production model that collapses and combines the production option into the development option.

Capitalizing rather than expensing development costs (such as intangible drilling costs) creates incentives to do projects that have a lower probability of success, that have shorter well lives, and that have lower development costs. This shift in incentives creates a nonneutrality, causing investors to develop some properties prematurely while unduly delaying the development of other projects. These effects are apparent both from calculating development threshold prices and from examining the nature of the pool of projects developed immediately after exploration. Capitalizing development costs also causes a slight increase in the exploration threshold price and therefore reduces exploration. These effects are present whether the dominant "external" tax is a cash flow tax or an accretion tax.

Although it is quite apparent that these tax effects are present, their economic significance is not clear. Determining this significance will require simulations over a large set of possible price paths. The variation in the tax effects over different price paths is of interest as well as the aver- 
age tax effect. ${ }^{96}$

Capitalizing rather than expensing exploration costs (such as the costs of seismic analysis of potential underground deposits) results in a more complicated pattern of effects. This policy causes a large increase in the exploration threshold price, thereby reducing exploration. Since the taxpayer will not recover capitalized exploration costs until development, this policy also reduces the cost of development and lowers development threshold prices. As a consequence, capitalizing exploration costs results in more intensive development and production of known reserves as well as reduced exploration. This pattern is undesirable if the goal is to enhance national security by encouraging the creation of a pool of reserves that are available for immediate exploitation in case foreign supplies become unavailable.

It also is possible that taxpayers may be able to circumvent most of the impact of rules require capitalization of exploration costs by strategically realizing losses. This possibility may blunt the undesirable national security impact of such rules, but the costs of the associated trading are social costs that would not arise under expensing.

Capitalizing exploration costs also causes distortions in development project choice that are similar to the distortions caused by capitalizing development costs. However, the distortions from capitalizing exploration costs are smaller because the after-tax impact of development costs is much larger than the tax benefits available at the development stage from capitalized exploration costs.

\section{APPENDIX: DERIVATIONS}

This Appendix derives the formulae set forth in the text and the formulae required to compute the values presented in the tables. Section A develops the net present value and option price formulae, Section B the threshold price formulae, and Section $C$ the tax parameter formulae. Section D details the computation of an upper bound for the value of the tax losses connected with the development option.

\section{A. Deriving Net Present Value and Option Value}

We shall derive threshold prices, the prices at which it is optimal to exercise various options. Doing so is a standard exercise in continuous time finance. ${ }^{97}$ The value of production, development and exploration options will depend on the current price of the mineral and on the stochastic properties of that price. Focusing on crude oil, we begin with a stochastic process that describes the evolution of price over time. In par-

96. For a more detailed description of the potential use of simulations, see supra text accompanying notes 35-36.

97. An elementary reference is David C. Shimko, Finance in Continuous Time (1992). The specific methods used here are described very well in DixiT \& PINDYCK, supra note 37. 
ticular, as discussed in the text, ${ }^{98}$ we assume that the oil price process is driven by geometric Brownian motion:

$$
d P=\alpha P d t+\sigma P d z
$$

This equation means that prices tend to increase at the rate $\alpha$, but the rate is subject to a normally distributed perturbation with mean zero and variance $\sigma^{2} d t$. If the required expected return on oil projects is $\mu$, then $\delta=\mu$ $\alpha$, is the opportunity cost for delaying exercise of the option. The idea is that oil in the ground appreciates in value at an expected rate of $\alpha$ but one can expect to earn $\mu=\delta+\alpha$ if the option is exercised and the oil is immediately available for sale or use. ${ }^{99}$ The oil price, $P$, depends on time, $t$. Nonetheless, for the sake of notational simplicity, we suppress the time dependence, writing $P$ instead of $P_{t}$ or $P(t)$.

Now consider a well. Assume that the well contains $R$ in reserves, that it will take time $T$ to produce all of the reserves, that the extraction rate is constant, that the cost of drilling the well is $I_{d}$, that operating costs are zero, and that the well cannot be restarted if it is shut down. Under these assumptions, the operators will continue to run the well until all of the reserves are depleted once they start production.

In this case, the value, $V$, of the well will depend on the oil price, $P$, and the elapsed time, $t$, since production began. So $V=V(P, t)$. Since $P$ evolves via geometric Brownian motion, and since cash flow is at the rate $R P / T$, the following partial differential equation holds for $V: 100$

$$
\frac{1}{2} \sigma^{2} P^{2} V_{P P}+\alpha P V_{P}-\mu V-V_{t}+\frac{R P}{T}=0 .
$$

The solution to this equation is: ${ }^{101}$

$$
V(P, t)=\frac{R P}{T(\mu-\alpha)}\left[1-e^{-(\mu-\alpha)(T-t)}\right]=\frac{R P}{\delta T}\left[1-e^{-(\mu-\alpha)(T-t)}\right]
$$

Subtracting the well cost yields the formula for net present value as stated in the text:

$$
N P V(P, t)=\frac{R P}{\delta T}\left[1-e^{-(\mu-\alpha)(T-t)}\right]-I_{d} .
$$

98. See supra note 11 and accompanying text.

99. If the option were a standard call option based on the price of a common stock, $\ddot{a}$ would represent the expected dividend rate and $a$ the expected rate of capital gains. Holding the option means giving up the dividend return during the holding period. See DixIT \& PINDYCK, supra note 37, at 149. For an oil project, the terminology is different. Holding a production option rather than producing means giving up the "convenience yield" of having oil immediately available for sale or use. See id. at 178-79.

100. See Shimko, supra note 97, at 20,36, 40. Using Shimko's notation for the parameter values, our case involves $a=1 / 2 \sigma^{2}, b=\alpha, c=-\mu, d=-R / T$, and $e=m=n=0$.

101. See id. at 41. 
This formula for net present value ignores taxes and assumes that only one well is required to drain the reserves. In the text model, taxes reduce revenues by the proportion $(1-s-\eta s)$ where $s$ is the tax rate and $\eta$ the percentage depletion proportion that apply. In addition, costs will be reduced by the proportion $(1-s)$ if the taxpayer can expense the costs and by the proportion $\left(1-s\left(1-e^{-r t}\right) / r T\right)$ where $\mathrm{r}$ is the after-tax interest rate if the taxpayer must capitalize the costs. ${ }^{102}$ As a result, the formula for net present value becomes:

$N P V(P, t)=\frac{(1-s+\eta s) R P}{\delta T}-r T\left[1-e^{-(\mu-\alpha)(T-t)}\right]-N I_{d}\left[\left(1-c_{d}\right)(1-s)+c_{d}\left(1-s \frac{1-e^{-r(T-t)}}{r(T-t)}\right)\right]$

where $c_{d}$ is one if development costs are capitalized and zero if they are expensed.

We now consider the value of the option to produce the oil reserves from the well. Until exercise of the option, there are no cash flows, and upon expiration, the option will be worthless. As a result, the value of the production option will have the following functional form: ${ }^{103}$

$$
F_{3}(P)=A_{1} P^{\beta_{1}}+A_{2} P^{\beta_{2}}
$$

where $\beta_{1}>0>\beta_{2}$. The option must decrease in value as the oil price $P$ falls. As a result, $A_{2}=0$, and the functional form for the option value is simply:

$$
F_{3}(P)=A_{1} P^{\beta_{1}}
$$

At the threshold price, "value-matching" and "smooth-pasting" conditions must apply. I.e., the value of the option to produce must be equal to the net present value of immediately undertaking production, and the derivative with respect to price of the option value and the production value must be equal. ${ }^{104}$ Value matching means that the threshold price $P_{3}{ }^{*}$ must satisfy $F_{3}\left(P_{3}{ }^{*}\right)=N P V\left(P_{3}{ }^{*}, 0\right)=V\left(P_{3}{ }^{*}, 0\right)-I_{d}$. The smooth pasting condition means that the derivatives of both sides of the value matching relationship must be equal. For our case (with $N=1$ and $s=0$ ), the value matching condition implies:

102. For a detailed discussion of these tax adjustments, See supra text accompanying notes $26-27$.

103. The functional form and threshold price of the production option are denoted with a subscript " 3 ." The motivation is that production is the third stage. The first stage is exploration and the second is development. Functional forms and threshold prices for those stages will have subscripts " $I "$ and " 2 " respectively.

104. If the option is worth more than the value of producing, it is not optimal to exercise the option. As soon as the production value exceeds the option value, the option holder should exercise. It is not optimal to hold onto the option when its value is less than the value of producing immediately. The necessity of the smooth-pasting condition for optimality is more complicated. For a good discussion, see Avinash K. Dixir, ThE ArT of Smooth Pasting 36-37 (1993). 


$$
A_{1} P_{3}^{{ }^{*} \beta_{1}}=\frac{R P_{3}^{*}}{\delta T}\left[1-e^{-\delta r}\right]-I_{d}
$$

The smooth-pasting condition implies:

$$
\beta_{1} A_{1} P_{3}^{*\left(\beta_{1}-1\right)}=\frac{R}{\delta T}\left[1-e^{-\delta T}\right]
$$

Solving these two conditions for $P_{3}{ }^{*}$ and $A_{1}$ yields:

$$
P_{3}^{*}=\frac{\beta_{1}}{\beta_{1}-1} \frac{\delta T I_{d}}{\left(1-e^{-\delta T}\right) R}
$$

and

$$
A_{1}=\left(\frac{\beta_{1}-1}{I_{d}}\right)^{\beta_{1}-1}\left(\frac{R\left(1-e^{-\delta T}\right)}{T \beta_{1} \delta}\right)^{\beta_{1}}
$$

It also is possible to show that: ${ }^{105}$

$$
\beta_{1}=\frac{1}{\sigma^{2}}\left[\left(\frac{\sigma^{2}}{2}-r-\delta\right)+\sqrt{\left(\frac{\sigma^{2}}{2}-r+\delta\right)^{2}+2 \sigma^{2} r}\right]
$$

where $r$ is the after-tax riskless rate.

The numbers in Table I of the text were computed using these formulae (with $s=0$ and $\mathrm{N}=1$ ) for net present value, the value of the production option, and the threshold price for the production option.

\section{B. Deriving Threshold Prices for the Development and EXPLORATION OptIONS}

The derivation of the formula for the development option is very similar to the derivation of the formula for the production option in the previous Section. The first step in development is drilling a test well. In the model developed in the text, the test well will indicate either that production is feasible or that there are no recoverable reserves. The model relies on the assumption that all production traits (reserves, time required to recover the reserves, number of wells required, etc.) are known prior to drilling the test well. As noted in the text, this assumption means that the owner will not begin development unless success (a test well indicat-

105. See Dixit \& PINDYCK, supra note 37, at 152. 
ing production is feasible) would lead to immediate production. ${ }^{106}$ As a consequence, we know that the threshold price for the development option, $P_{2}^{*}$, must be greater than or equal to the threshold price for the production option, $P_{3}{ }^{*}$.

The same reasoning applied in the case of the production option reveals that the functional form of the value function for the development option is:

$$
F_{2}(P)=C_{I} P^{\beta_{1}} .
$$

where $C_{1}$ is a constant. Value matching means that the threshold price $P_{2}{ }^{*}$ must satisfy $F_{2}\left(P_{2}^{*}\right)=\left[Q \cdot N P V\left(P_{2}^{*}, 0\right)\right.$ - expected cost of development $]$ where $Q$ is the probability that production will be feasible. The smooth pasting condition means that the derivatives of both sides of the value matching relationship must be equal.

To arrive at an expression for the expected cost of development, observe that there is a probability $Q$ that development will succeed and the owner will drill $N$ wells at a before-tax cost of $I_{d}$ each to produce the reserves. With probability $1-Q$, development will not succeed, and the owner's before-tax expenditure will be only $I_{t}$, the cost of the test well that indicated failure. As a consequence, after-tax expected cost will be:

$$
\begin{aligned}
& Q N I_{d}\left[\left(1-c_{d}\right)(1-s)+c_{d}\left(\frac{1-e^{-r T}}{r T}\right)\right] \\
& -Q s I_{e}\left[c_{r}\left(\frac{1-e^{-r T}}{r T}-1\right)+c_{e}\left(\frac{1-e^{-r T}}{r T}\right)\right] \\
& +(1-Q)\left(I_{t}(1-s)-c_{e} I_{e} s\right)
\end{aligned}
$$

where $c_{r}$ is one if exploration costs are expensed with recapture and zero otherwise, and $c_{e}$ is zero if exploration costs are expensed and one if capitalized. The first term is the after-tax cost of drilling $N$ development wells multiplied by the probability, $Q$, that such drilling is warranted.

The second term captures the impact that the decision to develop has on the treatment of exploration expenditures. On a pre-tax basis, these expenditures are a sunk cost and have no further effect on value. However, capitalization of these costs (or "expensing with recapture") results in a tax impact at the time of development. In the case of expensing with recapture $\left(c_{r}=1\right)$, the owner expensed the exploration costs but must take them back into income at the time development begins and then recover them again, capitalized over the development period. This has a

106. Otherwise, delaying development until the oil price is high enough to warrant immediate production allows the owner to earn interest on the development cost. See supra note 49. 
negative effect proportional to the difference between the present value of one dollar of capitalized costs and one dollar of present income. This difference is the factor in parentheses that multiplies $c_{r}$ in the expression above. Alternatively, if the law required exploration expenses to be capitalized $\left(c_{e}=1\right)$, they cannot be recovered until development begins. The owner receives a development "bonus" in the form of lower after-tax costs due to the fact that exploration costs finally may be written off. This aspect is captured by the second term in the second set of square brackets in the expression above.

The final term in the expression for expected cost reflects the outcome when the test well indicates that production is not feasible. Thus, this term begins with $(1-Q)$, the probability of that outcome. The rest of the term reflects the after-tax cost of the test well, $I_{t}(1-s)$, and the fact that if exploration costs were capitalized $\left(c_{e}=1\right)$, the owner may now write them off, gaining $I_{e} s$ after-tax.

The same reasoning applied in the previous Section to derive the threshold price for the production option yields the following expression for the threshold price of the development option:

$$
P_{2}^{*}=\frac{\beta_{1}}{\beta_{1}-1} \frac{\delta T}{\left(1-e^{-\delta T}\right)} \frac{1}{R Q(1-s+\eta s)} x\left[\begin{array}{c}
Q N I_{d}\left(\left(1-c_{d}\right)(1-s)+c_{d}\left(\frac{1-e^{-r T}}{r T}\right)\right) \\
-Q s I_{e}\left(c_{r}\left(\frac{1-e^{-r T}}{r T}-1\right)+c_{e}\left(\frac{1-e^{-r T}}{r T}\right)\right) \\
+(1-Q)\left(I_{t}(1-s)-c_{e} I_{e} s\right)
\end{array}\right]
$$

where $\beta_{1}$ has the same value as indicated in the previous Section. ${ }^{107}$ This expression generates all of the numbers in Tables V-VIII and X-XVI in the text.

The basic approach for finding the threshold price for the exploration option is similar but with the additional complication described in detail in the text: exercising the exploration option means that the owner will pay to draw a development option at random. ${ }^{108}$ The exact traits of the prospect such as recoverable reserves, the probability of development success, the number of wells required to drain the reserves, and the time required for recovery are not known until after the draw occurs. Suppose that oil prices increase to $P_{1}^{*}$, the threshold price for exercising the exploration option. Exercise results in learning the parameters $(R, T, Q, N)$ of the prospect and in receiving a development option. That option will have its own threshold price, $P_{2}^{*}$. Depending on the parameter values

107. This formula is the same as the one for $P_{3}^{*}$, the threshold price for the production option, except that the expected cost expression in the big square bracket replaces the single well cost $I_{d}$ and revenues $\left(P_{3}{ }^{*} R\right)$ are adjusted to be after-tax by multiplying by the tax factor $(1-s-\eta s)$. This tax factor appears in the denominator after solving for the threshold price.

108. See supra text accompanying note 79 . 
$(R, T, Q, N)$, there are two cases. If these parameter values produce a very good prospect (high $R$, low $T$, high $Q$, low $N$ ), then $P_{2}{ }^{*}$ will be less than or equal to $P_{I}^{*}$, and the owner will develop the project immediately Define the set $M=\left\{R, T, Q, N: P_{2}^{*}(R, T, Q, N) \leq P_{l}{ }^{*}\right\}$ and $\operatorname{Pr}(M)=\operatorname{Pr}\{(R, T, Q, M)$ $\in M\}$ as the probability of being in that set. Similarly, if the parameter values are less favorable, $P_{2}{ }^{*}$ will be greater than $P_{l}{ }^{*}$, and the owner will not proceed with development immediately but will have a development option exercisable in the future. Denoting the region of $R-T-Q-N$ space where this result obtains as " $L$," the probability of being in this region is $\operatorname{Pr}(L)=\operatorname{Pr}\{(R, T, Q, N) \in L\}$.

I assume that $s=0$ in order to simplify the derivation. It is easy to alter the final result to include the tax parameters. In addition, define $V(P, R, T, N)$ to be the present value of production when the oil price is $P$ and the prospect has traits $R, T$, and $N$. Using the same reasoning as for the production and development options, the value of the exploration option will have the functional form:

$$
F_{1}(P)=D_{1} P^{\beta_{1}}
$$

where $D_{l}$ is a constant. The value matching equation will be:

$$
F_{1}\left(P_{1}^{*}\right)=E\left(F_{2}\left(P_{1}^{*}\right)\right)-I_{e}
$$

where $E($.) denotes expectation over the full range of $(R, T, Q, N)$ values and $I_{e}$ is the cost of exploration. The smooth-pasting condition will equate the derivatives of the two sides of the value matching equation.

We know that:

$$
F_{2}\left(P_{1}^{*}, R, T, Q, N\right)= \begin{cases}C_{1}(R, T, Q, N) P_{1}^{* \beta} & \text { if }(R, T, Q, N) \in L \\ Q N V\left(P_{1}^{*}, R, T, N\right)-Q N I_{d}-(1-Q) I_{t} & \text { if }(R, T, Q, N) \in M\end{cases}
$$

Defining $E_{L}($.$) as expectation conditional on being in region L$ and $E_{M}($. as expectation conditional on being in region $M$, the value matching equation becomes:

$$
D_{1} P_{1}^{* \beta_{t}}=E_{L}\left(C_{1}\right) P_{1}^{* \beta_{1}} \operatorname{Pr}(L)+E_{M}\left[Q N V-Q N I_{d}-(1-Q) I_{t}\right] \operatorname{Pr}(M)-I_{e}
$$

where we suppress the arguments in $C_{I}($.$) and V($.$) for convenience. The$ smooth-pasting condition is:

$$
\beta_{1} D_{1} P_{1}^{{ }^{* \beta_{1}-1}}=\beta_{1} E_{L}\left(C_{1}\right) P_{1}^{{ }_{1} \beta_{1}-1} \operatorname{Pr}(L)+E_{M}\left[Q N V_{P}\right] \operatorname{Pr}(M) .
$$

Multiplying the value matching equation by $\beta_{l}$ and subtracting $P_{1}{ }^{*}$ times the smooth-pasting condition yields:

$$
\left[\left(\beta_{1}-1\right) E_{M}(Q N V)-\beta_{1} E_{M}(Q N) I_{d}-\beta_{1} E_{M}(1-Q) I_{t}\right] \operatorname{Pr}(M)=\beta_{1} I_{e}
$$


using the fact that $P_{1}{ }^{*} \mathrm{~V}_{\mathrm{P}}=\mathrm{V}$ since $V$ is linear in $P$. Rearranging using the expression for $V$ when $N$ wells are required to drain reserves yields:

$$
\left[\frac{\beta_{1}-1}{\beta_{1}} P_{1}^{*} E_{M}\left(Q R \frac{1-e^{-\delta T}}{\delta T}\right)-E_{M}(Q N) I_{d}-E_{M}(1-Q) I_{t}\right] \operatorname{Pr}(M)=I_{e} \text {. }
$$

Adding in the tax parameters in the same way as we did for the development option transforms this equation into the equation in the text:

$$
\left[\begin{array}{c}
\frac{\beta_{1}-1}{\beta_{I}} P_{I}^{*} E_{M}\left\{Q R \frac{1-e^{-\delta r}}{\delta T}\right\}(1-s+\eta s) \\
-(1-s) I_{d} E_{M}\left\{Q N\left(\left(1-c_{d}\right)+c_{d} \frac{1-e^{-r T}}{r T}\right)\right\} \\
+s I_{e} E_{M}\left\{Q\left(c_{t}\left(\frac{1-e^{-r T}}{r T}-1\right)+c_{e}\left(\frac{1-e^{-r T}}{r T}\right)\right)\right\} \\
-\left(I_{t}(1-s)-s c_{e} I_{e}\right) E_{M}\{(1-Q)\} \\
-I_{e}\left(1-s\left(1-c_{e}\right)\right) \\
=0 .
\end{array}\right] x \operatorname{Pr}(M)
$$

Since the conditional averages in the equation and $\operatorname{Pr}(M)$ depend on $P_{1}^{*}$, it is not possible to solve the equation directly for $P_{1}^{*}$. Instead one begins with a trial value for $P_{1}^{*}$, say $P^{*}$, and then estimates the conditional averages, estimates $\operatorname{Pr}(M)$, and, simultaneously, estimates whether $P^{*}$ is close to being correct using a technique called Monte Carlo integration. This technique is required because it is not possible to calculate the conditional averages or $\operatorname{Pr}(M)$ independently. ${ }^{109}$ For a given trial value, $P^{*}$, one draws projects at random from the set of all possible projects. If the project is one that an investor would develop immediately, one computes the value of the difference in the equation above. ${ }^{110}$ If $P^{*}$ is correct (that

109. The conditional averages are integrals that are defined in the four-dimensional space of parameters $R, Q, N$, and $T$. The goal is to integrate over the region where these parameters result in a project that one will develop immediately, given $P^{*}$. The boundaries of this region are very complicated and depend on $P^{*}$ itself. Under Monte Carlo integration, the approach is to draw points at random from the four-dimensional parameter space and test whether each point is a set of parameters for a project that an investor would develop immediately. If so, the point is included in constructing the conditional averages.

110. This computation requires an estimate of $\operatorname{Pr}(M)$. The procedure begins by making a preliminary estimate of $\operatorname{Pr}(M)$ using a random sample of eight hundred points from the 
is, equal to $P_{1}{ }^{*}$ ), then this difference, which we will call "the residual," should be zero on average. The procedure continues picking projects at random and develops a mean estimate for the residual along with a standard deviation of the estimate. When the standard deviation becomes small enough, the associated estimate of the residual is taken to be the residual produced by $P^{*}$. A separate algorithm then evaluates whether this residual is small enough, or whether it would be desirable to test another trial value for $P_{1}{ }^{*}$. 111

Using this approach means that the solutions for $P_{1}{ }^{*}$ are not exact. The degree of precision depends on how large the standard deviation of the residual estimate is permitted to be. Most of the computations that underlie the tables below require that the standard deviation of the residual be one half of one percent of the exploration cost, $I_{e}$. For $I_{e}=\$ 100,000$, this means that $95 \%$ of the time, the answer will be the right answer for some $I_{c}$ within $\$ 1000$ of the $\$ 100,000$ figure. Some numerical experiments indicate that this sensitivity results in values for $P_{1}^{*}$ that are (with high probability) within a penny or two of being correct.

A side benefit of the Monte Carlo approach is that it is easy to compute the statistical characteristics of the pool of projects developed immediately and of the projects that will be developed if the oil price moves some fixed amount above $P_{1}^{*}$.

\section{Deriving Tax Adjustments for Return Parameters}

As discussed in the text, tax adjustment of the return parameters depends on the tax treatment of the large "external" sector consisting of all assets other than oil and gas properties. ${ }^{112}$ The need to adjust the return parameters arises when the external tax is an accretion tax but not when the external tax is a cash flow income tax. Assume that the pre-tax riskless rate in the external sector is $r_{p}$ and that the pre-tax risk premium in the external sector is $\gamma_{p}$. The goal will be to derive $r$ and $\gamma$, the riskless rate and risk premium applicable to the oil and gas sector.

An accretion tax reduces the riskless rate by the tax rate. As a result, owners will discount riskless after-tax returns in the oil and gas sector by

$$
r=\left(1-t_{A}\right) r_{p}
$$

where $t_{A}$ is the rate for the accretion tax in the external sector.

Deriving the adjustment for the risk premium is more complicated. Consider a "perpetual" well that produces $R$ of reserves every year with-

parameter space. The preliminary estimate is equal to the proportion of the eight hundred sample projects that an investor would develop immediately. As the procedure runs, more random sampling occurs. The estimate of $\operatorname{Pr}(M)$ is updated each time the procedure picks another sample point from the parameter space.

111. The algorithm is "Brent's method." This algorithm is reasonably fast but also will find a solution when the underlying function is choppy or discontinuous. See William PRESS ET AL., supra note 40, at 251 . Brent's method is particularly appropriate here since the residual is bouncing around randomly.

112. See supra text accompanying notes $45-46$. 
out depletion. The reasoning in Section A of this Appendix indicates that value will be proportional to the revenue flow rate and that the revenue flow rate is itself proportional to the oil price, $P$. Under the simplifying assumption that $R=1$, cash flow will be $P$ per year, and it will be true that $V=b P$ for some constant $b$. Return, $\theta$, consists of cash flows and capital gains. After a short time period, $d t$, return includes payment for oil production during the period at the price $P+d P$ that applies at the end of the period ${ }^{113}$ plus the capital gain $d V$ induced by the change in oil price $d P$. The rate of return is:

$$
\frac{d \theta}{V}=\frac{d V+P+d P}{V}=\left(1+\frac{1}{b}\right) \frac{d P}{P}+b .
$$

The stochastic term $d P / P$ is scaled by the factor $(1+1 / b)$. Suppose that the appropriate $b$ on a pre-tax basis would be $b^{*}$. Then, $b^{*}=1 /\left[r_{p}+\gamma_{p}-\right.$ $\alpha]$, and $\left(1+1 / b^{*}\right)=1+r_{p}+\gamma_{p}-\alpha$, where $\alpha$ is the expected rate of increase in oil prices. ${ }^{114}$ Revenues in the oil and gas sector are subject to cash flow taxation at the time of production. There will be a constant $b$ such that $V$ $=b X$, but, in general, $b$ will not be equal to $b^{*}$. The pre-tax risk factor $\gamma_{p}$ will shift by the ratio $(1+1 / b) /\left(1+1 / b^{*}\right)$ to an after-tax risk factor.

Given the relationship $d P=\alpha P d t+\sigma P d z$ and that the solution $V=b P$, we have the following equation: ${ }^{115}$

$$
\left[r\left(1-t_{A}\right)+\gamma_{p} \frac{(1+1 / b)}{\left(1+1 / b^{*}\right)}\right] V=\alpha P V_{P}+P
$$

113. Another choice would have been to assume that the price existing at the beginning of the time interval $d t$ applies for all production during the time period. This assumption would result in a coefficient of 1 for the $d P / P$ term in the text, and there would be no correction for the pre-tax risk premium in the case where there is an external accretion tax. The correction in that premium is small compared to the correction for the riskless rate since the riskless rate is corrected by the factor $1-t_{A}$ while the correction for the risk premium is (roughly) by a factor of $t_{A} r_{p}$, smaller by almost two orders of magnitude. This alternative adjustment factor for the risk premium would not significantly change the results in the text comparing outcomes under the two different external taxes since the impact on the riskless rate applicable to the oil sector is the main difference between them.

Choice of intermediate points (at the beginning, in the middle or at the end of a small time interval) generally will have an effect on stochastic integrals (such as the one for the value of the oil production here). See Ludwig Arnold, Stochastic Differential. Equations: Theory and Applications 59-61 (1974). However, the linearity of the results here means that the value equation would be unaffected by the choice of intermediate point. See id. at 169, Equation (10.2.6) (connection between stochastic integrals using different intermediate values depends on second-order partial derivatives of the integrandlinearity means there is no difference). However, the choice of intermediate point does affect the correction factor for the risk premium.

114. See Sнimko, supra note 97, at 21. In Shimko's computation with our notation, there is no risk, and $b^{*}=1 /\left(r_{p}-\alpha\right)$. Under the external accretion tax, we must add the risk premium $\gamma_{p}$ to $r_{p}$.

115. See id. at 20. 
Substituting for $\left(1+1 / b^{*}\right)$ and using the fact that $V_{P}=b$ and $V=b P$, we have:

$$
\left[r\left(1-t_{A}\right)+\gamma_{P} \frac{(1+1 / b)}{\left(1+r_{p}+\gamma_{p}-\alpha\right)}\right] b P=\alpha b P+P .
$$

Solving for $b$ yields:

$$
b=\frac{1}{r_{p}\left(1-t_{A}\right)+\gamma_{p}\left(1-\frac{r_{p} t_{A}}{1+r_{p}-\alpha}\right)-\alpha} .
$$

In a pre-tax world or in the case where a cash flow tax applies to the external sector and to the oil sector, the required expected return on oil projects would be $\mu=r_{p}+\gamma_{p}$. As a result, $\delta=\mu-\alpha=r_{p}+\gamma_{p}-\alpha$, and $V=$ $b^{*} P$ where $b^{*}=1 /\left[r_{p}+\gamma_{p}-\alpha\right]=1 / \delta$. For an oil and gas sector subject to cash flow taxation embedded in a large external sector where accretion taxation applies, we have $b$ as above and $b=1 / \delta$ where:

$$
\delta=r_{p}\left(1-t_{A}\right)+\gamma_{p}\left(1-\frac{r_{p} t_{A}}{1+r_{p}-\alpha}\right)-\alpha .
$$

\section{The Value of Tax Losses Connected with the DEVELOPMENT OPTION}

A rule requiring the owner to capitalize exploration costs means that the owner will not receive any deductions for those costs until development begins. In contrast a rule permitting expensing means that the owner may deduct the entire amount of the exploration costs immediately. Under the capitalization rule, the initial basis of the development option will equal the total exploration cost. Since exploration gives the owner a "draw" from a pool of development options, a bad draw will result in a development option that is worth much less than the basis at the time exploration is completed. In that case, the owner may sell the development option, realizing a loss equal to a portion of the exploration cost. In effect, this owner will have expensed part of that cost. In addition, after sale, there is the possibility of further losses if the option drops below the sale price. In effect, the buyer has a "tax timing option," the ability to sell and take losses when an asset declines in value. In the case where the development option is worth more than the exploration cost when exploration is completed, the owner would have a similar tax timing option. The development option may decline to a value less than the exploration cost in the future, permitting the owner to sell and realize tax losses at that time. 
The value of current and future tax losses at the time of exploration effectively shifts the capitalization rule towards an expensing rule. An intuitive way to quantify this shift is to compare the impact of tax losses to the case where exploration costs are partially expensed and losses have no tax impact. For example, if the value of loss-taking is equivalent to expensing half the exploration cost and capitalizing the rest, potential loss-taking shifts the capitalization rule halfway toward expensing.

In order to compute an upperbound on the value of loss-taking, we assume that transaction costs for trading the development option are zero. With zero transaction costs, a taxpayer facing a constant marginal tax rate will want to realize all losses as they occur. Taking losses as early as possible rather than waiting results in earlier tax benefits, the best strategy in the face of positive interest rates and a constant tax rate. When exploration is completed, there is a loss case (where the ensuing development option is worth less than the exploration cost) and a gain case (where the ensuing development option is worth more than the exploration cost). In the loss case, the taxpayer will want to sell immediately and then buy an equivalent development option to maintain the same portfolio of mineral properties. ${ }^{116}$ The sale will result in a tax loss, and there will be a timing option associated with the replacement development option (assumed identical to the one given up in the sense of having the same $R, N, T$, and $Q$ ). In the gain case, the holder of the development option will not have a tax incentive to sell immediately, but there will be a valuable tax timing option associated with the development option.

Valuing loss-taking for the development option requires valuing the tax timing option associated with the development option. We estimate the tax timing option value by using a formula developed in a paper by George Constantinides for the case of equities under the assumption of zero transaction costs. ${ }^{117}$ Under the formula, five parameters determine the value of the tax timing option: the riskless interest rate, the variance of the equity price, the dividend rate, a measure of the frequency of "forced liquidations," and the applicable tax rate. The model underlying the formula assumes that equities must be liquidated (regardless of tax status) with a certain probability during each period under a Poisson process. The force parameter for the Poisson process is the measure of the frequency of forced liquidations that appears in the formula. Forced liquidation ends the scope for taking further tax losses. If forced liquidations are frequent, the tax timing option will have lower value. The

116. We are assuming that taxpayer engages in a wash sale to abstract away from portfolio adjustment issues. The restrictions on losses on wash sales in I.R.C. $\$ 1091$ do not apply since the development option is not a "stock" or a "security." If all taxpayers trading development options are subject to the same tax rules, including the same marginal tax rate, then the value of the tax timing option will be capitalized into the price of the option. As a result, the seller will realize this value regardless of whether the seller engages in a wash sale or simply sells without purchasing an equivalent property.

117. See Constantinides, supra note 53. 
parameter for the frequency of such liquidations ranges from 0 (no forced liquidations) to infinity (continuous liquidations). We set this parameter equal to zero consistent with the goal of establishing an upper-bound for the impact of loss-taking. ${ }^{118}$

The riskless interest rate, dividend rate, and tax rate are the same as the values used in the simulations described in the text.119 Since we are applying the formula to the development option, we need to use the variance of the value of the development option, not the underlying variance of the oil price. We know that the value of the development option takes the form:

$$
F_{2}(P)=C_{1} P^{\beta_{1}} \text {. }
$$

where $C_{l}$ is a constant. Given that the oil price process is driven by geometric Brownian motion, $d P=\alpha P d t+\sigma P d z$, by Ito's Lemma: ${ }^{120}$

$$
d F_{2}=\left[\alpha \beta_{1}+\frac{1}{2} \sigma^{2} \beta_{l}\left(\beta_{1}-1\right)\right] F_{2} d t+\sigma \beta_{1} F_{2} d z
$$

As a result, the appropriate variance for valuing loss taking for the development option is $\left(\sigma \beta_{1}\right)^{2}$ rather than $\sigma^{2}$.

Given the five parameters, we use Constantinides' formula for the value of an equity as a function of current price and basis. ${ }^{121}$ Under the assumption of no forced liquidations, the value of the timing option as a proportion of the variance is simply:

$$
\Gamma=\frac{V\left(F_{2}, B_{2}\right)-V\left(F_{2}, 0\right)}{B_{2}}
$$

where $V\left(F_{2}, B_{2}\right)$ is the value of a development option to an owner who purchased at price (and has tax basis equal to) $B_{2}$ when a buyer would pay $F_{2}{ }^{122}$ The numerator represents the difference between the value when the owner engages in strategic loss-taking less the value when the owner holds the option forever. Since the denominator is the tax basis, $\Gamma$ is normalized per unit of dollar paid for the option. Applying Constantinides formula and simplifying yields:

$$
\Gamma=\frac{s}{1-m}\left(\frac{F_{2}}{B_{2}}\right)^{m}
$$

118. There is an event in the model of this article that is similar to a forced liquidation. In the case of the development option, if oil prices increase enough, the option will be exercised, cutting off future possibilities for loss-taking. This event will reduce the value of the tax timing option. As mentioned supra in note 86 , computing the amount of value reduction would be very difficult, and I leave this task for future research.

119. See supra text accompanying notes 63-64.

120. See Sнimко, supra note 97 , at 13-16.

121. See Constantinides, supra note 53, at 620 (equation (10)). Given we are assuming no forced liquidations, we can set $\lambda=0$ in equation (10), greatly simplifying the expression.

122. As a result, the value function must obey the identity $V(F, F)=F$. 
where $s$ is the applicable tax rate, and $m$ is the negative root of a quadratic equation whose coefficients are functions of the five parameters listed above. ${ }^{123}$

Taking averages in a run with a large number of draws, we obtain the following values:

\begin{tabular}{|c|c|c|}
\hline \multicolumn{3}{|c|}{ Components and Totals for Value of Loss-taking } \\
\hline & $\begin{array}{l}\text { Case: Exploration costs } \\
\text { capitalized; development } \\
\text { costs expensed }\end{array}$ & $\begin{array}{l}\text { Case: Exploration and } \\
\text { development both } \\
\text { capitalized }\end{array}$ \\
\hline $\begin{array}{c}\text { probability of delayed } \\
\text { development }\end{array}$ & 0.910 & 0.916 \\
\hline $\begin{array}{c}\text { proportion with value } \\
\text { less than exploration } \\
\text { costs conditional on } \\
\text { delayed development }\end{array}$ & 0.586 & 0.580 \\
\hline $\begin{array}{c}\text { average loss in "loss } \\
\text { case" as a proportion of } \\
\text { exploration costs }\end{array}$ & 0.832 & 0.832 \\
\hline $\begin{array}{c}\text { average tax timing } \\
\text { option value in loss case }\end{array}$ & 0.055 & 0.055 \\
\hline $\begin{array}{c}\text { average tax timing } \\
\text { option value in gain case }\end{array}$ & 0.230 & 0.229 \\
\hline $\begin{array}{c}\text { average total value of } \\
\text { loss-taking conditional } \\
\text { on delayed development }\end{array}$ & 0.323 & 0.321 \\
\hline $\begin{array}{c}\text { average total value of } \\
\text { loss-taking conditional } \\
\text { on delayed development, } \\
\text { reduced by probability of } \\
\text { delay }\end{array}$ & 0.294 & 0.294 \\
\hline
\end{tabular}

The first line indicates that development is delayed about $91 \%$ of the time after exploration is completed. Assuming development should be delayed, about $58 \%$ of the time the development option will be worth less than the exploration costs, creating an immediate tax loss for the owner. The average loss in such instances is large, about $83 \%$ of the exploration costs-creating a reduction in taxes equal to $.40 \times .83=33.2 \%$ of the exploration costs. The tax timing option in loss cases is worth about $5.5 \%$ of the exploration costs on average. In the case where the development option is worth more than the exploration costs expended, the average

123. See Constantinides, supra note 53, at 620 . 
value of the tax timing option is about $23 \%$ of the exploration costs. Combining these numbers weighted by the appropriate probabilities yields an average total value of loss-taking equal to $32 \%$ of exploration costs conditional on delayed development. Expensing would have resulted in a value equal to $40 \%$ of exploration costs since $40 \%$ is the tax rate. As a result, conditional on delayed development, the possibilities for loss-taking are equivalent to expensing $80 \%$ of the exploration costs and capitalizing the rest (without being able to take losses). The last row in the table indicates that if we adjust for the fact that development is delayed $91 \%$ of the time, the $32 \%$ figure falls to around $29.4 \%$ and the $80 \%$ figure to about $75 \%$.

It is possible to run the simulations to compute threshold exploration prices under the assumption that $80 \%$ of the exploration costs are expensed and the rest capitalized (with no ability to take tax losses). Not surprisingly, the values for threshold exploration prices in these runs move $80 \%$ of the way from the high level that results from assuming exploration expenses are capitalized to the low level under the assumption that exploration costs are expensed. I do not report these simulations here. 


\section{Comments}




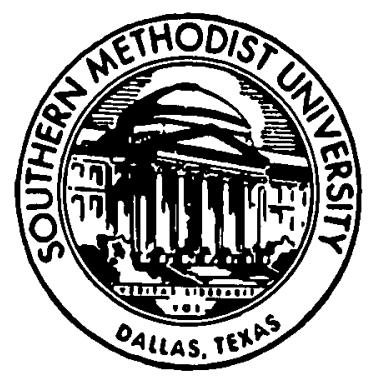

